\title{
LA DELEGACIÓN DEL GOBIERNO VASCO EN NUEVA YORK DURANTE LA GUERRA CIVIL (1936- 1939): LAS LABORES DE LOBBYING ANTE LA NCWC Y EL DEPARTAMENTO DE ESTADO
}

\author{
The Delegation of Basque Government in New York during \\ the Spanish Civil War (1936-1939): The Lobbying Actions \\ with the NCWC and the US State Department
}

\author{
David Mota Zurdo \\ davidmotazurdo@gmail.com \\ Universidad del País Vasco / Euskal Herriko Unibertsitatea. España
}

Fecha de recepción: 31/05/2016

Fecha de aceptación: 20/01/2017

RESUMEN: En este artículo se analizan las relaciones políticas que estableció la delegación del Gobierno vasco en Nueva York con diferentes agencias norteamericanas durante la Guerra Civil española, entre ellas la National Catholic Welfare Conference y el Departamento de Estado. Este estudio se aborda desde la óptica de la Historia Política y aporta fuentes novedosas procedentes de archivos norteamericanos (National Archives and Records Administration, American Catholic University Archive, Rockefeller Foundation Archive) y estatales (Centro del Patrimonio Documental de Euskadi-Irargi, Archivo Histórico del Nacionalismo Vasco y Archivo General de la Administración); gracias a ellas se profundiza en el estudio de la acción exterior vasca durante esta etapa. Finalmente, se esbozan unas breves conclusiones sobre la efectividad de las iniciativas vascas para presionar a los organismos estadounidenses mencionados y mostrarles su perspectiva, la republicana, sobre la Guerra Civil española.

Palabras clave: Gobierno vasco; Guerra Civil española; National Catholic Welfare Conference; Departamento de Estado; Estados Unidos.

ABSTRACT: In this article it is analyzed the political relations between the Basque Government delegation in New York and the National Catholic Welfare Conference and US State Department during the Spanish Civil War. This Study it is presented from the Political History point of view and 
contributes sources from the American archives (National Archives and Records Administration, American Catholic University Archive, Rockefeller Foundation Archive) and from the Spanish state archives (Basque Documentary Heritage Center-Irargi, Historical Archive of Basque Nationalism and General Administration Archive); thanks to these sources, it is analyzed in the study of the Basque External Action during this period. Finally, it is sketched brief conclussions about the efficacy of th basque initiatives to lobby the US agencies mentioned and to show them its perspective, the loyalty, about the Spanish Civil War.

Keywords: Basque Government; Spanish Civil War; National Catholic Welfare Conference; State Department; United States of America.

Sumario: 1. Introducción. 2. Las relaciones con la embajada de la República española y la cuestión del embargo. 3. En busca de aliados cantifranquistas?: lobbying ante la NCWC y el Departamento de Estado. 4. Financiación para los refugiados, contra-propaganda y proyectos de actuación. La nonata sección americana de la LIAB. 5. Conclusiones. 6. Bibliografía.

\section{INTRODUCCIÓN}

Meses después del inicio de la Guerra Civil, tras un largo proceso estatutario iniciado en septiembre de 1931 durante la II República, nació, en octubre de 1936, el primer Gobierno vasco autónomo ${ }^{1}$. Previamente a la toma de Bilbao por el ejército franquista, en junio de 1937, su objetivo prioritario se concentró, lógicamente, en el esfuerzo bélico. Sin embargo, no descartó otras cuestiones, como la acción exterior, que a la postre fue fundamental para la articulación y mantenimiento del Ejecutivo vasco en el exilio². Desde la creación del Gobierno vasco en octubre de 1936 hasta su forzoso exilio en junio de 1937, primero a Cataluña y luego a Francia, se fundaron numerosas delegaciones del Gobierno Vasco en Europa y América, muchas de las cuales prosiguieron con su actividad a lo largo de la II Guerra Mundial y de la Guerra Fría ${ }^{3}$. Con todo, aquí se prestará especial atención a la delegación vasca en Nueva York.

${ }^{1}$ Granja, 2003, p. 224; Núñez, 2006, p. 357. Respecto a la etapa republicana es de referencia obligada la obra de Fusi, Juan Pablo (2002). El País Vasco 1931-1937: autonomía, revolución y guerra civil, Madrid: Biblioteca Nueva. Id. (1984). El País Vasco: pluralismo y nacionalidad, Madrid: Alianza. Id. (1979). El problema vasco en la II República, Madrid: Turner.

2 Ugalde, 1996; Núñez, 1995a , 1995b.

${ }^{3}$ Las delegaciones en territorio no español fueron las de París, Bayona, Londres, Nueva York, Bruselas y México. Las dos primeras tuvieron la misión de ser cabeza de puente entre el territorio autónomo vasco y el mundo exterior, así como su labor de auxilio a los exiliados. La belga duró de septiembre de 1937 a marzo de 1938 y se dedicó a la gestión propagandística y a la atención de los niños vascos acogidos por las organizaciones católicas y de izquierdas. La delegación mexicana funcionó débilmente durante los primeros años, limitándose a actividades comerciales y de propaganda. Goiogana, 2009, pp. 85-86; Ugalde, 2000. Álvarez, O. y Sanz E. 2011, pp. 2-4. 
En el año 1938 se creó, a expensas de Manuel María de Ynchausti y bajo la dirección de Antón Irala y Manuel de la Sota Aburto, la delegación del Gobierno vasco en la Gran Manzana4. Según han señalado los principales especialistas, ésta quedó conformada por un delegado, Antón Irala -responsable de la política y la diplomacia-, un secretario, Manuel de la Sota McMahon -coordinador de las actividades- y diferentes vocales, entre los que se encontraban, Ramón de la Sota McMahon $^{5}$. En ella también participaron Juan Aramburu (periodista), Eustacio Arritola (sacerdote), José Urresti -cuñado de Manuel de la Sota y tesorero de la delegación- y, previamente a la fundación de la delegación, Thomas Abelló quién había organizado la asociación "The American Friends of the Spanish Basques» para combatir la propaganda pro-franquista del padre Talbot, del que finalmente se supo que era un infiltrado pro-franquista que pretendía minar desde dentro las actividades de la delegación ${ }^{6}$.

A lo largo de este artículo se analizan tres ámbitos fundamentales en los que participó la delegación vasca en Nueva York para hacer frente al franquismo en Estados Unidos. De hecho, se estudian las labores paradiplomáticas utilizadas por los delegados vascos, primero, ante las instituciones republicanas españolas en Estados Unidos, luego, ante el Departamento de Estado y, posteriormente, ante la National Catholic Welfare Conference (NCWC).

\section{LAS RELACIONES CON LA EMBAJADA DE LA REPÚBLICA ESPAÑOLA Y LA CUESTIÓN DEL EMBARGO}

Los delegados vascos se establecieron en Nueva York en un momento realmente difícil, tanto para el Gobierno vasco como para el Gobierno republicano español. A finales de 1938 el ejército sublevado prácticamente había ganado la guerra, la división en el seno de los políticos republicanos españoles cada vez se hacía más patente y el Gobierno de Euzkadi en Cataluña preparaba un plan de evacuación masiva hacia Francia. En Estados Unidos todavía se dejaba sentir la crisis económica producida por el crack bursátil de 1929 -crisis que las medidas del New Deal de Roosevelt habían permitido detener y reconducir, pero que no se cerraría hasta

${ }^{4}$ La sede era el Hotel New Weston de Nueva York. Goiogana y Bernardo, 2006, p. 109; Garrido y Lekuona, 2006, pp. 138-147.

${ }^{5}$ Ordaz, 1995, pp. 179- 198; San Sebastián, 1991, p. 15.

${ }^{6}$ Goiogana y Bernado, 2006, pp. 108-111. El padre Talbot fue un católico estadounidense favorable a Franco que dirigió el semanario de los jesuitas America e impulsó durante la Guerra Civil española la «America Spanish Relief Fund», un fondo de ayuda para la zona franquista. Rey, 1996, pp. 129-150.

7 Denominación oficial del Gobierno Vasco durante la II República y el exilio. 
la entrada del país en la II Guerra Mundial y el desarrollo de una economía de guerra-, con índices de paro mantenidos entre un 16-20\% durante los años treinta, y con un aumento de la tensión social y laboral que permitió ganar peso en esta década al movimiento obrero y extender la sindicación a la industria del acero y del automóvil; de hecho, se ha calificado a los treinta en Estados Unidos de "periodo revolucionario» ${ }^{8}$.

En este contexto, la mayoría de la sociedad estadounidense se posicionó del lado de la República ante el conflicto español, aunque dentro de los sectores católicos las opiniones se dividieron, pues hubo quien consideró la guerra como una lucha contra el ateísmo y la impiedad. Estos sectores eran un problema para Roosevelt, en primer lugar, porque necesitaba el voto de los católicos para mantener la estabilidad de su gobierno; $y$ en segundo lugar porque el progresismo estadounidense le solicitaba que estudiara la posibilidad de revocar el embargo de armas impuesto a España a finales de 1936, que tanto estaba marcando el curso de la guerra a favor de los sublevados ${ }^{9}$. Ante esta situación, el presidente estadounidense debía actuar con cautela, pues la NCWC apoyaba el mantenimiento del embargo. También, una política orientada hacia el levantamiento del bloqueo del comercio de armas a España podría dificultar las relaciones de la Casa Blanca con Berlín y Roma, e incluso ir en contra del sector aislacionista del Congreso de Estados Unidos, que había apoyado la decisión tomada por Francia y Gran Bretaña de mantener la neutralidad ante el conflicto español ${ }^{10}$. Contribuyó a complicar la situación la contaminación informativa de los periódicos y revistas del grupo Hearst que desde julio de 1936 defendieron la no intervención de Estados Unidos en la Guerra Civil española y mostraron al Gobierno de la República como punta de lanza de la bolchevización de Europa. En esta coyuntura, en mayo de 1937, Estados Unidos renovó el Acta de Neutralidad, una ampliación de las disposiciones acordadas conjuntamente por el Congreso respecto a España en enero del mismo año y relativas a las restricciones al comercio de armas con países que se encontraran en guerra, incluyendo la prohibición a los ciudadanos estadounidenses de viajar en barcos de naciones beligerantes ${ }^{11}$.

No obstante, detrás del enfrentamiento entre los partidarios de revocar el embargo y sus defensores había un debate de gran calado. La intervención

8 Jenkins, 2002, p. 283. Respecto a las tasas de desempleo, algunos autores han establecido cifras cercanas al 25 por ciento: Stiglitz, 2004, p. 25; Alonso, 1990, pp. 41 y ss.

9 Bosch, 2012, pp. 181-216; Thòmas, 2007, pp. 38-56.

10 López Zapico, 2008, p. 60; Bosch, 2012, pp. 208 y ss.; Moradiellos, 2001, p. 95 y ss.; Montero, 2009, pp. 63-95; Alpert, 1996, pp. 12-20; Rey, 1997.

${ }^{11}$ Conde y Burns, 2001; Anderson, 2003. No obstante, cabe señalar que las empresas estadounidenses Texaco, Ford, Studebaker y General Motors, cuyos productos no estaban contemplados en la lista de prohibiciones del acta de no intervención, sí abastecieron al bando franquista durante el desarrollo de la contienda. García Nieto y Tuñón de Lara, 1981, T. 9, p. 286. 
en España retomaba las propuestas wilsonianas de participación en los asuntos europeos como garantía de la propia seguridad de Estados Unidos del mantenimiento de la paz internacional, cuestionando así el tradicional aislacionismo estadounidense. Esta posición había quedado expresada ya en algunos de los discursos ofrecidos por Roosevelt durante su campaña presidencial, como el conocido discurso de la cuarentena de Chicago, en los que intentó convencer a sus potenciales votantes de que la participación de Estados Unidos en el escenario internacional podía ser decisiva para la defensa de los intereses de su país ${ }^{12}$.

A pesar de ello, la política exterior de Estados Unidos siguió dominada hasta 1941 por el principio de no intervención en los asuntos internacionales, como reclamaba la mayoría de la opinión pública del país. Lo que le llevó a mantener el embargo sobre España fue la creencia de que así podría mantenerse al margen de las hostilidades en Europa, bajo «la convicción de que la carrera armamentística había llevado a la Primera Guerra Mundial y que el desarme podía llevar a la paz» ${ }^{13}$.

Desde el inicio de la Guerra Civil, el Gobierno de la República tenía representación diplomática en Washington DC, dirigida por Fernando de los Ríos, pero también el bando sublevado -aunque no reconocida por el Gobierno estadounidense-, a cargo de Juan Francisco de Cárdenas, exdiplomático republicano. A finales de 1936, se había creado en dicha ciudad la Subdelegación de Prensa y Propaganda del Gobierno de la España franquista, formada por Cárdenas y por Miguel Echegaray -también exdiplomático republicano- y el falangista Javier Gaytán de Ayala. Un año después la Subdelegación cambió de nombre y pasó a denominarse Peninsular News Service ${ }^{14}$. Ésta fue una auténtica tapadera para el desempeño de las tareas propagandísticas propias de una embajada, que no podía constituirse legalmente debido a que el Gobierno de Franco no había sido reconocido por Estados Unidos, pero que no impedía que se dotaran de otros subterfugios o estructuras para el desempeño de funciones propagandísticas y de relaciones diplomáticas. Para evitar problemas derivados de tal situación alegal, esta oficina de información se constituyó con periodistas estadounidenses afines a la causa franquista, como Russell Palmer ${ }^{15}$, Marcial

12 Kennedy, 2005, p. 482. Respecto al discurso de la cuarentena véase: Roosevelt, 1937.

${ }_{13}$ Bosch, 2009, p. 445. Respecto al idealismo wilsoniano véase: Aron, 1973, pp. 30-33; Ambrosius, 2002.

${ }^{14}$ Moreno, 2008, p. 542.

${ }^{15}$ Rusell Palmer rodó la primera película a color que se conserva de la Guerra Civil, titulada The War in Spain, que incluía imágenes de Guernica bombardeada que, según su versión, había sido quemada por los «rojos». Pablo, 2006, pp. 287-289. 
Rosell, Joseph M. Bayo y Francis X. Connelly ${ }^{16}$. Ellos firmaron los artículos publicados en las revistas Cara al Sol y Spain-editadas por la Peninsular News Service y publicadas de manera bimensual entre octubre de 1937 y noviembre de 1939-, con intención de sortear "las suspicacias de los grupos opositores, reticentes a las publicaciones extranjeras que pudiesen atentar contra los principios que inspiraban a la democracia estadounidense ${ }^{17}$. También se llevó a cabo esta iniciativa para evitar ser blanco de las críticas de asociaciones proclives al Gobierno republicano, como las Sociedades Hispanas Confederadas (SSHHCC) y el North American Committee to Aid Spanish Democracy (NACASD) ${ }^{18}$. Y también porque a los seguidores de Franco no les interesaba perder una vía de financiación como la American Spanish Relief Fund, dirigida por el padre Talbot, John J. M. O'Shea, Ogden Haamond y John Eogan Kelly ${ }^{19}$.

La situación fue bastante más complicada para Fernando de los Ríos ${ }^{20}$. El político socialista había sido elegido embajador de la República tras la dimisión en septiembre de 1936 de Luis Calderón por diferencias de opinión con el Gobierno de la misma. Desde el momento en que presentó sus credenciales ante el presidente Roosevelt, su labor diplomática mantuvo una premisa básica: defender de manera clara, tranquila, y mostrando vehementemente su fe en los principios democráticos, que su Gobierno no era ni comunista ni anti-católico ${ }^{21}$. La tarea propagandística del profesor De los Ríos estuvo en constante pugna con la desplegada por los sublevados, que contaban con la solidaridad moral del catolicismo estadounidense. Por esto, las gestiones que realizó para lograr el levantamiento del bloqueo estadounidense al comercio de armas resultaron infructuosas y no pudo evitar que la situación se complicara con la renovación del Acta de Neutralidad de $1937^{22}$.

En este contexto, el 12 de agosto de 1938, el lehendakari Aguirre escribió al embajador De los Ríos explicándole que se asentaría en Nueva York una delegación

${ }^{16}$ Archivo General de la Administración (AGA). Alcalá de Henares, España. Sig. (10) 26.02 54/8840. Informe confidencial de Juan Francisco de Cárdenas sobre la creación del Comité de Relación con los grupos estadounidenses amigos de la nueva España, 26 de marzo de 1940, Washington.

17 Moreno, 2008, p. 592.

18 Estas organizaciones recaudaron fondos y financiaron giras de conferenciantes, como la de José Bergamín o la del sacerdote católico irlandés y antiguo dirigente del Sinn Fein, Michael O’Flanagan, con objetivos propagandísticos para la República española. Véase González 2010, pp. 267-309; Sánchez, 1992, pp. 207-216.

${ }^{19}$ American Spanish Relief Fund recaudó en torno a los 100.000 dólares en 3 años. González, 2010, p. 297.

20 Véase sobre de los Ríos: Ruíz Manjón, 2007; Zapatero, 1999.

${ }^{21}$ Fox, 2010, p. 158.

22 Fox, 2010, p. 159 y ss. 
del Gobierno vasco formada por Irala y los dos De la Sota. El envío de esta delegación resultaba acorde con la estrategia diseñada por el Gobierno de Euzkadi para tratar de ayudar a la victoria de la República contra Franco y para buscar el apoyo de las potencias occidentales (Francia, Gran Bretaña y Estados Unidos) al restablecimiento -en un futuro no muy lejano- del autogobierno vasco ${ }^{23}$. El lehendakari estimó conveniente que Antón Irala y Manuel de la Sota se entrevistaran a su llegada a Nueva York con el embajador De los Ríos -como así hicieron el 24 de agosto- para evitar que se abrieran posibles tensiones entre ambas delegaciones diplomáticas. El presidente Aguirre se dirigió en este sentido a Fernando de los Ríos:

Ya conoce usted la forma en que hemos actuado en Francia, en Bélgica y en Inglaterra, así como en otros países, con evidente provecho para nuestro Pueblo Vasco y para la República. Por eso esta propaganda ha de ser llevada independientemente por la organización vasca, para entrar en aquellos medios en los que hemos penetrado en Europa y hemos de penetrar en América [...]. Principalmente nuestra preocupación es el medio católico [...]. Estos delegados, hombres jóvenes y trabajadores, son como adelantados de otra comisión de más edad y de mucha preparación que saldrá en cuanto estos hombres hayan preparado convenientemente el terreno. [...] Los Sres. Irala y de la Sota llevan instrucciones concretas de tenerle a usted al corriente de todo cuanto hagan y de los resultados e impresiones que obtengan. [...] Es muy importante que los organismos afectos a la República que ahí se mueven, sean discretamente advertidos de la finalidad de nuestros enviados para que no vean en ellos una misión extraña, sino convergente a los mismos fines, aun cuando empleando procedimientos diversos, mirando precisamente a la eficacia de la propaganda ${ }^{24}$.

El Gobierno de la República no se opuso a la apertura de la delegación del Gobierno de Euzkadi en Nueva York, al igual que no lo había hecho con similares establecimientos en Londres y París ${ }^{25}$. En las fechas en que la delegación fue abierta - finales de agosto

${ }^{23}$ San Sebastián, 2014, pp. 100 y ss. Para mayor profundización Jiménez de Aberasturi, 1999, pp. 357 y ss.

${ }^{24}$ Centro de Patrimonio Documental de Euskadi-Irargi. Bergara, España. GE 0041-05. Carta de José Antonio Aguirre a Fernando de los Ríos, 12-8-1938, París.

${ }^{25}$ Alexander Ugalde ha señalado que esto mismo sucedió con la de París, donde la delegación del Gobierno de Euzkadi se dirigió en varias ocasiones a la embajada republicana para disponer de ciertos recursos, y con la de Londres, donde la delegación vasca se estableció en los locales de la embajada española. Ugalde, 1996, p. 196. De hecho, la República estaba especialmente interesada en fomentar la propaganda del Gobierno vasco, que podía llegar a campos donde el Gobierno central era incapaz de influir. Así lo demuestra que la embajada republicana en París financiara en parte el cine documental producido por el Gobierno vasco en Francia. Véase Pablo, 2006, pp. 79 y ss. 
de 1938- Fernando de los Ríos y otros miembros de la embajada republicana seguían convencidos de que la política de embargo con respecto a España se revocaría de un momento a otro. En este sentido apuntaba la información enviada por el subsecretario de Estado, Sumner Welles, al embajador español, así como las declaraciones hechas por Roosevelt sobre la conveniencia de realizar pequeñas modificaciones en su política que ayudaran a contrapesar el aislacionismo del Congreso porque «in battle to defend the democracies the United States frontier was the Rhine ${ }^{26}$. Incluso Cordell Hull, había señalado que «la legislación existente [...] representaba un triste, limitado y recortado estatuto interno que reducía la esencia del derecho internacional y de la práctica diplomática [y] confería un beneficio gratuito a los probables agresores» ${ }^{27}$.

Hasta el momento, la representación diplomática del Gobierno republicano había tenido dificultades para moverse en un terreno mediático dominado por la propaganda pro-franquista, que incidía sobre aspectos como la persecución religiosa en España y la teórica fuerza del Partido Comunista en el Ejecutivo español, de manera que la labor propagandística que se proponía desplegar la delegación vasca en Nueva York podía ser provechosa no solo para el Gobierno de Euzkadi sino también para el de la República. El proyecto propagandístico de dicha delegación tenía como objetivo preferente la actuación sobre la opinión pública católica, en cuyo interior podrían difundir una nueva imagen de la República española, al presentarla en estrecha relación con el católico Gobierno vasco. Esto beneficiaría también a su imagen ante el Departamento de Estado, un tanto desgastada por la escasa efectividad de los contactos mantenidos por De los Ríos y el exembajador de Estados Unidos en España Claude G. Bowers con los secretarios Hull y Welles ${ }^{28}$.

Para poder llevar a cabo su misión, lo primero que hicieron los comisionados vascos fue inscribirse como agentes de un gobierno extranjero en el Departamento

26 "Roosevelt causes stir», The Albany Advertisment, 6-2-1939.

27 Kennedy, 2005, pp. 501-502.

${ }^{28}$ Fox, 2010, p. 168. Claude G. Bowers fue embajador de Estados Unidos en España entre 1933 y 1939. Periodista e historiador de formación y miembro del Partido Demócrata. Durante la Guerra Civil española, fue muy crítico con la política de no intervención de su Gobierno ante un conflicto que definió como levantamiento fascista. Simpatizante de los nacionalistas vascos de los que destacó su catolicidad, singularidad y nobleza, plasmó su experiencia como embajador en España en un libro de memorias titulado My Mission to Spain. En abril de 1939, dimitió de su cargo cuando Estados Unidos reconoció la España franquista como Gobierno legítimo. Durante la II Guerra Mundial fue nombrado embajador estadounidense en Chile. Desde allí apoyó como pudo las iniciativas de los dirigentes vascos en Nueva York para sacar al lehendakari Aguirre de la Europa ocupada. Asimismo, informó de la potencialidad de la propaganda ideológica nazi y fascista en Chile en detrimento de la británica y la estadounidense. Su labor como diplomático en este país está recogida en su libro Chile through Embassy Windows, 1939-1953. Respecto a la misión diplomática que encabezó Bowers en España, así como su relación con los nacionalistas vascos, véase Bowers, 1977. 
de Estado, bajo el previo asesoramiento de William P. Mangold ${ }^{29}$, periodista de la revista política The New Republic ${ }^{30}$, director de la Spanish Information Bureau ${ }^{31}$ y activo participante en labores de lobbying a favor de la República junto a Herbert Southworth ${ }^{32}$. Mangold favoreció el funcionamiento de la delegación vasca y así puso en conocimiento de sus responsables que, según la Foreing Agent Registration $A c t^{33}$ aprobada a principios de 1938, cualquier representante legal de un gobierno extranjero debía inscribirse como agente en la Immigration and Naturalization Service del Departamento de Justicia ${ }^{34}$. Con esta medida, sumada a las leyes restrictivas de la inmigración aprobadas años antes, el Gobierno de Estados Unidos quería limitar la entrada de posibles elementos subversivos ${ }^{35}$. En esta tarea trabajó incesantemente John Edgar Hoover, director del FBI, que estaba obsesionado por descubrir supuestas organizaciones clandestinas de comunistas, anarquistas y socialistas preparadas para atacar al Gobierno de Estados Unidos. Así, siguiendo el consejo del director del Spanish Information Bureau, y dado que Estados Unidos

${ }^{29}$ Algunos autores han señalado que era el jefe de la Spanish Information Office. Jiménez de Aberásturi, 1999, p. 473.

${ }^{30}$ Revista estadounidense de ideología progresista dedicada a la política y al arte fundada por Walter Lippman y Herbert Croley, que destacó por tener un amplio número de lectores entre la clase media y por su capacidad de influencia sobre las decisiones del Gobierno de Estados Unidos. Michael Straight, amigo de Ramón de la Sota y agente del KGB durante la Guerra Fría, dirigió esta revista. Conklin, 1936; Wickenden, 1994.

31 Esta organización dependía directamente de Fernando de los Ríos y publicaba el periódico News of Spain con el objetivo de presionar sobre la opinión pública estadounidense. Durante febrero de 1938 publicó varios artículos sobre la guerra civil española en los que se destacaron los bombardeos sobre civiles en Barcelona y las protestas suscitadas al respecto en la opinión pública estadounidense. Herbert Southworth, a petición de De los Ríos, trabajó para esta organización, en conexión con Jay Allen (periodista del Chicago Tribune), muy bien relacionado con los socialistas Juan Negrín, Luis Araquistáin, Julio Álvarez del Vayo y Rodolfo Llopis. Aunque la actividad de esta organización fue muy limitada, fue el centro neurálgico de la propaganda del gobierno republicano. Spanish Information Bureau, 18 de febrero de 1938, Spanish Civil War, McMaster University Libraries de Ontario http://pw20c.mcmaster.ca/spanish-informationbureau-periodical-19-february-1938. López Zapico, 2008, p. 110.

32 Rey, 1996, p. 138.

${ }^{33}$ El Acta de Registro de Agentes Extranjeros (FARA, en sus siglas inglesas) fue promulgada en 1938. FARA era el estatuto que requerían aquellas personas que actuaran como agentes políticos de gobiernos extranjeros, en calidad de representantes políticos, con la obligación de presentar una relación de actividades, recibos y reembolsos relacionados con sus actividades, facilitando así la evaluación que debía realizar el Gobierno de Estados Unidos. FARA formaba parte de la Sección de Contraespionaje (CES) de la división de Seguridad Nacional (NSD) dependiente del departamento de Justicia y era responsable del cumplimiento de la ley. http://www.fara.gov (consultado el 5-3-2015).

\footnotetext{
34 Ordaz, 1998, p. 130.

${ }^{35}$ Bosch, 2005, pp. 243 y ss.
} 
no reconocía al Gobierno de Euzkadi como representante de un Estado de pleno derecho, Antón Irala se inscribió como agente del Gobierno de la República española el 22 de octubre de 1938, casi dos meses después de su llegada a Estados Unidos, lo suficientemente tarde como para levantar sospechas en la agencia dirigida por Hoover ${ }^{36}$.

Después de legalizar el status de la delegación, el primer movimiento de los Sota e Irala fue romper toda relación con Thomas Abelló, en quien no confiaban plenamente, y de quien sospechaban que fuera un colaborador de Franco, como decía la información proporcionada por Bowers y conseguida por este de los consulados de Estados Unidos en Barcelona y París. Abelló estaba dispuesto a unirse a los republicanos para obtener desde dentro información sobre las actividades de los leales a la República, y el FBI le seguía los pasos desde que, a partir del inicio de la Guerra Civil española, había comenzado a proporcionarles información sobre las actividades de los nacionalistas vascos que se reunían en el restaurante Jai Alai ${ }^{37}$. Su relación con Irala se explicaba por su interés en destapar una organización, posiblemente vasca, de falsificadores de pasaportes que se encontraba en Francia y que proporcionaba la salida, desde Barcelona -donde el Gobierno vasco tenía su sede oficial- y con salvoconductos falsos, de políticos, sindicalistas e intelectuales republicanos -los, por él catalogados, comunistas- con destino a América ${ }^{38}$. La intromisión de Abelló fue detectada gracias a la colaboración de los contactos de Ynchausti en el Departamento de Estado, especialmente de Claude Bowers. Sin embargo, la información que Abelló había proporcionado al FBI había podido dañar la imagen del Gobierno vasco en Washington.

Por otra parte, en estas mismas fechas, se esperaba la llegada de una comisión enviada por el Partido Nacionalista Vasco (PNV), dirigida por José Luis de la Lombana, cuya finalidad sería la de recaudar fondos y realizar labores de propaganda. Teniendo en cuenta el contexto, la aparición de esta comisión podría enmarañar la situación. Oportunamente, el lehendakari indicó al Euskadi Buru Batzar (EBB) que la delegación del PNV desistiera de cualquier representación en Estados Unidos, primando así a la representación asentada previamente en Estados Unidos y encabezada por Irala y los Sota, porque, según la estrategia política de Aguirre, la unidad de acción, evitando duplicidades, debía ser la seña de identidad de la acción vasca en el extranjero. De

${ }^{36}$ Ordaz, 1995, p. 182.

37 National Archives and Records Administration (NARA). College Park, Maryland (Estados Unidos). RG 84, Foreign Service, US Consulate Barcelona (1937-1939), Box. 47, Leg. 820.07, Abelló, Thomas P. Carta de J. Edgar Hoover, director del FBI, al secretario de Estado Hull, 10 de enero de 1938, Washington DC.

38 NARA. College Park, Maryland (Estados Unidos). RG 84 Foreign Service, US Consulate Barcelona (1937-1939), Box. 47, Leg. 820.07, Abelló Thomas P. Carta de Robert D. Murphy (cónsul de Estados Unidos en París) a Douglas Flood (vice-cónsul de Estados Unidos en Barcelona), 8 de febrero de 1938 París. 
hecho, el solapamiento de actividades entre ambas delegaciones podría debilitar al Gobierno vasco «perdiendo la personalidad exterior que hoy tiene gracias a su independencia económica ${ }^{39}$. El Ejecutivo vasco y el PNV debían dar ejemplo de unidad ante la comunidad vasco-americana, que estaba dividida entre pro-republicanos y carlistas, y, ahí las juntas extraterritoriales del PNV cobraban especial relevancia. Respecto a las recaudaciones, el lehendakari aseguró al EBB que llegaría a un acuerdo con el PNV para distribuir los fondos obtenidos; por eso, exigió a la directiva del partido que diera la orden a sus organizaciones de que se pusieran a disposición de la delegación del Gobierno vasco, brindándoles su ayuda y orientación ${ }^{40}$.

A su llegada a Estados Unidos, una de las primeras actividades de Irala y los Sota había sido la búsqueda de fuentes de financiación para el Gobierno de Euzkadi, pero también el impulso de una campaña propagandística sobre la comunidad católica internacional, siguiendo las directrices emprendidas por el Ejecutivo de Aguirre durante la Guerra Civil. Su objetivo era mostrar al Departamento de Estado y a la opinión pública estadounidense que la alianza del Gobierno vasco, integrado y presidido por católicos, con la República obedecía a que ésta era el régimen legítimo establecido en España. Así pues, el primer acercamiento hacia los políticos y personalidades estadounidenses se realizó a través del envío del periódico Euzko Deya (París) y de obras propagandísticas que denunciaban la intervención alemana e italiana en la guerra, la persecución del clero y de la población civil por motivos ideológicos, los orígenes de la cuestión vasca, y las razones del surgimiento del nacionalismo vasco. El establecimiento de un tibio contacto inicial, sin que fuera muy comprometido, se hacía con vistas a conseguir la simpatía de personas que ocupaban una significativa posición dentro del Departamento de Estado, de la sociedad estadounidense o de los medios de comunicación. Para ello utilizaron una lista de contactos facilitada por Ynchausti que les permitió entablar contacto con Jay Allen (periodista del Chicago Tribune), John T. Bernard (congresista por el Estado de Minnesota), Bruce Bliven (editor de The New Republic), Franz Boas (profesor de la Columbia University), Homer T. Bone (senador por Washington), Arthur Capper (senador por Kansas), George Mundelein (cardenal de la diócesis de Chicago), Fernando Careaga (diplomático del consulado español en Chicago), Albert Einstein, David Efron (encargado de la Spanish Bureau), e incluso pro-franquistas como Francis $X$. Talbot (sacerdote jesuita, director de la revista America) o el conocido sacerdote discordante Charles E. Coughlin ${ }^{41}$. La mayoría se suscribieron a Euzko Deya e incluso

39 Archivo Histórico del Nacionalismo Vasco (AHNV). Fundación Sabino Arana, Bilbao, España. EBB-392-3. Acta de reunión del EBB celebrada en Anglet, 23-8-1938.

40 Ibíd.

${ }^{41}$ Irargi. Bergara, España. GE-0041-05. Fichero de propaganda realizado por los comisionados vascos Sota e Irala en Estados Unidos durante 1938, Nueva York. Véase también San Sebastián, K. (1991). The Basque Archives, op. cit., p. 33. 
hubo algunos que solicitaron copias de obras como The Tree of Gernika de George Steer. También hubo casos, como el de Talbot y Alfred E. Smith, que se negaron a recibir Euzko Deya, al igual que las principales universidades católicas, como Notre Dame (Indiana) y la Catholic University of America (Washington DC).

Aunque los beneficios obtenidos a través de este sistema de suscripciones no llegaron a superar los 200 dólares anuales, la delegación de Nueva York continuó con su envío por el interés en mantener una relación ordinaria con estas personalidades y con el objetivo de conseguir algún apoyo divulgando el posicionamiento del Gobierno de Euzkadi ante la guerra ${ }^{42}$. Como Irala había sostenido ante el lehendakari, se trataba de una carrera de fondo en la que las prisas no eran buenas compañeras. Si querían introducirse en las esferas de poder vinculadas con el sector católico y conseguir ayuda humanitaria y económica para los refugiados vascos debían avanzar con pies de plomo ${ }^{43}$.

\section{EN BUSCA DE ALIADOS ¿ANTIFRANQUISTAS?: LOBBYING ANTE LA NCWC Y EL DEPARTAMENTO DE ESTADO}

Desde el primer momento, la estrategia política de la delegación de Nueva York concentró su esfuerzo sobre los católicos estadounidenses. Sota e Irala estaban convencidos de que si conseguían el beneplácito de este sector social podrían presionar a la Administración Roosevelt para que levantase el embargo de armas a la República española y, además, conseguir una relación preferente con el Departamento de Estado que, en un futuro, ayudara a la recuperación del territorio vasco. Así lo expresó Antón Irala en octubre de 1938, tras la cumbre de Múnich:

[...] en el momento político actual y después de la crisis europea, nos parece que el único que podría hacer algo por la España Democrática es Roosevelt. Si el fin de la guerra de España se decide en Europa, Italia y Alemania con Inglaterra pueden imponer su decisión en contra de nuestros intereses [...]. La fecha en que finaliza el periodo de la ley sobre el embargo se acerca y los católicos (jesuitas) se están preparando para impedir que se levante ${ }^{44}$.

42 Carta de Antón Irala a José Antonio Aguirre, 27-12-1938, Boise (Idaho), en Anasagasti y Erkoreka, 2013, pp. 125 y ss.

${ }^{43}$ Irargi. Bergara, España. GE-0041-05. Carta de Antón Irala a José Antonio Aguirre, 13-111938, Nueva York.

${ }^{44}$ Irargi. Bergara, España. GE-0041-05. Carta de Antón Irala a José Antonio Aguirre, 5-101938, Nueva York. 
De cara a sumar apoyos para la República, la delegación vasca comenzó a planificar una serie de reuniones con representantes de la comunidad católica con el fin de que relajaran su postura favorable a la política de embargo de la Administración Roosevelt. Tales reuniones las llevarían a cabo en estrecha relación con otras mantenidas en Europa por representantes de la diplomacia del Gobierno de Euzkadi y del nacionalismo vasco, como el sacerdote Alberto Onaindía ${ }^{45}$, el jeltzale Francisco Javier Landaburu ${ }^{46}$ y el lehendakari Aguirre, entre otros. El mencionado clérigo vasco mantuvo contactos regulares con el cardenal Jean Verdier; el obispo de Dax, Clement Mathieu; el nuncio vaticano en París, Valerio Valeri; el filósofo católico francés Jacques Maritain; y el conocido político demócrata-cristiano Alcide De Gasperi, a quienes les dio a conocer lo sucedido en Guernica y les solicitó su colaboración ${ }^{47}$. Asimismo, Landaburu, que debía representar al Ejecutivo vasco en los foros internacionales, estableció conversaciones con los intelectuales franceses François Mauriac, Pierre Dumas y George Bernanos, con el mencionado Valeri, con el político socialdemócrata belga Paul Henri Spaak, y con Luigi Sturzo, fundador del democristiano Partido Popular italiano y exsecretario de la Acción Católica italiana ${ }^{48}$. Aguirre, por su parte, mantuvo reuniones con las más destacadas personalidades políticas francesas, como el primer ministro de Francia, Édouard Daladier, y el ministro de Asuntos Exteriores, George Bonnet; e inglesas, como el subsecretario de Asuntos Exteriores, Alexander Cadogan, o el presidente del Consejo de Ministros británico, Lord Edward Halifax ${ }^{49}$.

Gran parte de las personalidades con las que mantuvieron contacto en Europa tenían relación con el catolicismo, y la delegación sabía que estas relaciones eran una buena carta de presentación ante las fuerzas católicas de Estados Unidos. En el otoño de 1938 comenzaron las primeras reuniones con representantes del clero estadounidense. A mediados de septiembre se reunieron con el padre Francis $X$. Talbot e intentaron convencerle de que sus apreciaciones sobre el conflicto español eran erróneas; no se trataba de una cruzada contra el marxismo, como había declarado en más de una ocasión el director de la revista America, sino de un combate entre democracia y fascismo. Para los comisionados vascos, catolicismo y democracia estaban íntimamente unidos, así que explicaron a Talbot que la única postura ética que había podido tomar el Gobierno de Euzkadi, en referencia al

45 Sobre Onaindia Cal, 2012, pp. 193-215; Onaindia, 1974.

${ }^{46}$ Sobre Landaburu, Arrieta, 2009, pp. 199-220.

47 Cal, 2012, pp. 203-204.

${ }^{48}$ Arrieta, 2009, p. 202. De la misma autora véase Estación Europa. La política europeísta del PNV en el exilio (1945-1977) (Arrieta, 2007).

49 Telegrama de José Antonio Aguirre a Manuel Irujo, París, 22-7-1938, 2:00h, en Hills, 1984, pp. 279 y ss.; Miralles, 1994, pp. 113-141. 
PNV, ante la guerra era la del mantenimiento de su lealtad hacia la República ${ }^{50}$. Así explicaba Antón Irala al lehendakari su valoración sobre la reunión:

Me pareció interesantísima la entrevista, no porque le hayamos convencido para actuar con nosotros, cosa imposible en hombres de consigna, sino por que oyó verdades que siempre impresionan y producen efecto. [...]. Tendrías que haber visto a un hombre como el P. Talbot turbarse ante la presencia de tres $\operatorname{coitaos}^{51}$ y comenzar la conversación diciendo que no tienen nada contra los vascos, que es amigo, que ha recibido cartas de Roma hablándole de la verdad de nuestra postura, etc. [...]. Desde luego quedó impresionado y tendrá buen cuidado en no hablar contra los vascos ${ }^{52}$.

Por los términos en los que se debió de desarrollar la conversación y para procurar evitar cualquier tipo de enfrentamiento con Talbot -un hombre de ideas fijas y fiel a las directrices de su orden y de la NCWC, cuyos informes estaban muy valorados dentro de la jerarquía católica estadounidense-, los delegados optaron por otras alternativas de contactos. No obstante, habían dejado constancia ante Talbot de otra versión sobre las causas de la Guerra Civil y sus inmediatas consecuencias que, por lo menos, hizo que el jesuita estadounidense no volviera a calificar al Gobierno vasco como amoral y anticatólico.

Durante las semanas siguientes a esta primera reunión, Antón Irala contactó con Henry L. Binsse, director de la revista Commonweal, y con John Cort, secretario general de la Association of Catholic Tradeunionists (Asociación de Sindicalistas Católicos). La mayoría de editores y periodistas de la citada revista eran seguidores de las tesis filosóficas de Maritain en torno al humanismo cristiano e igualmente antifranquistas como, en buena manera, ya había demostrado George Nauman Shuster meses antes. Sin embargo, se habían declarado oficialmente neutrales, aun conociendo el posicionamiento de otras publicaciones europeas, también de esta línea editorial, como Sept, Espirit, Vie Intellectuelle, en las que habían trabajado, o aún lo hacían, pensadores como el propio Maritain, el mencionado George Bernanos y el también filósofo cristiano Emmanuel Mounier, y que habían defendido desde distintas perspectivas la actuación de los vascos en la guerra frente al modelo de catolicismo tradicional, autoritario y militarizado de los sublevados ${ }^{53}$. Durante la entrevista, el director Binsse instó a la delegación a que buscaran el

50 Irargi. Bergara, España. GE-0041-05. Carta de Antón Irala a José Antonio Aguirre, 21-91938, Nueva York.

${ }^{51}$ Coitao: buenazo.

52 Irargi. Bergara, España. GE-0041-05. Carta de Irala a José Antonio Aguirre, 21-9-1938, Nueva York.

53 Zanca, 2009, p. 159. 
apoyo de los católicos franceses -estrategia que ya habían iniciado antes de que la delegación llegara a Nueva York- para encauzar la mejora de sus relaciones con los estadounidenses. También les propuso a los delegados la publicación de un Ilamamiento a los católicos estadounidenses, realizado por el Comité National Catholique d'accueil aux Basques que encabezaba el cardenal Verdier, para conseguir el favor de la jerarquía católica estadounidense y obtener apoyos en la tarea de auxilio a los refugiados vascos que se encontraban en Cataluña y Francia ${ }^{54}$.

En el caso de la Association of Catholic Tradeunionists, mayoritariamente integrada por activos nacionalistas católicos irlandeses, como Frank P. Walsh -amigo personal de Roosevelt y conocido activista sindical que se había movilizado para que el Congreso trabajara por la aprobación de la Child Labor Ammendment que regulaba el trabajo infantil| ${ }^{55}$-, los delegados vascos se sirvieron del semanario The Catholic Worker de Dorothy Day, órgano de prensa del The New York Catholic Worker Movement -plataforma que a pesar de no formar parte de la asociación de sindicatos mantenía contactos con ella- que sostenía una línea editorial similar a Commonweal. Gracias a su colaboración lograron acceder al padre George Ford, capellán de la iglesia de la Columbia University ${ }^{56}$. Incluso, proyectaron la realización de gestiones ante el presidente de la República de Irlanda, Eamon de Valera, para conseguir su aval ante diferentes personalidades católicas irlandesas en Estados Unidos ${ }^{57}$.

Siguiendo las directrices apuntadas por Binsee, Irala se puso en contacto con el director del departamento legal de la NCWC, William Montavon. Meses antes, Montavon había hablado para la cadena de radio National Broadcasting Company (NBC), denunciando la persecución comunista en la zona republicana y recordando que Pío XI, sin aprobar por completo la insurrección armada, se había pronunciado hasta en dos ocasiones al respecto ${ }^{58}$. Montavon también había traducido al inglés la carta colectiva de los obispos españoles de 1937 en la que se manifestaba, entre otras cuestiones, que la propaganda -fundamentalmente republicana- había tergiversado las noticias sobre la guerra ${ }^{59}$. Montavon, como el resto de integrantes

${ }^{54}$ Irargi. Bergara, España. GE-0041-05. Carta de Antón Irala a José Antonio Aguirre, 28-91938, Nueva York.

55 Sealander, 2003, p. 150.

${ }^{56}$ San Sebastián, 1991, pp. 90 y 116.

57 Irargi. Bergara, España. GE-0041-05. Informe sobre puntos que pueden servir de base para nuevas gestiones a realizar en Estados Unidos del Norte de América, 2-3-1939, París.

${ }^{58}$ González, 2012, p. 321

59 Carta colectiva de los obispos españoles a todo el mundo con motivo de la guerra en España, en Redondo, 1993, pp. 310 y ss. Según este documento, la Iglesia católica no había conspirado en el conflicto, sino que, debido a la situación de persecución religiosa en la zona republicana -que habría sido acompañada de la revolución comunista-, la Iglesia se había visto abocada a solicitar su salvaguarda ante los sublevados. 
de la NCWC, tenía escaso margen de actuación ante el obispo Michael J. Ready, que era proclive a Franco.

Por decisión de Ready, Montavon había sido apartado de las apariciones públicas a raíz de una serie de polémicos asuntos a los que la NCWC se había visto obligada a dar respuesta, como el mensaje de Good Wishes (buenos deseos) que, el 31 de enero de 1938, sesenta congresistas estadounidenses enviaron al Gobierno republicano español ante la celebración de una nueva sesión de las Cortes, tras varios meses sin reunirse a causa de la guerra. La NCWC se sorprendió ante este mensaje y manifestó su disconformidad, al interpretar que este tipo de gestos hacia un gobierno que no toleraba la libertad de culto eran inadmisibles. Algo similar sucedió con respecto a los bombardeos de Barcelona por la aviación franquista. La NCWC no dudó en condenarlos, al igual que previamente había hecho el secretario de Estado Hull, no sin antes matizar que las instancias políticas estadounidenses no habían intervenido cuando en zona republicana habían sido fusilados miles de sacerdotes. En el verano de 1938, en plena efervescencia del debate sobre el levantamiento del embargo, Ready viajó a España para obtener información de primera mano. Durante su visita fue agasajado por el Gobierno de Franco, con el fin de convertirle en embajador de la causa nacional en Estados Unidos, cosa que consiguió, porque este volvió a Washington con una idea clara: si quería proteger a su país del comunismo, debía defender al cristianismo en España ${ }^{60}$. En consecuencia, la entrevista entre la delegación vasca y Montavon se presentaba difícil.

En la reunión, la delegación vasca pidió oficialmente a Montavon, en nombre del Gobierno de Euzkadi, la colaboración de la NCWC para desplegar un plan de asistencia a los refugiados vascos que se encontraban dispersos entre Europa y América. Montavon, cumpliendo órdenes de Ready, escuchó atentamente las proposiciones de Irala y acto seguido pidió explicaciones -ante la sorpresa del delegado vascosobre cuál era la relación que tenía el conocido nacionalista vasco José Luis de la Lombana con la asociación comunista Washington Friends of Spanish Democracy, que apoyaba al gobierno republicano de Juan Negrín ${ }^{61}$. Como ya he señalado, Lombana se encontraba en Estados Unidos porque había acudido como representante del PNV al II Congreso Internacional de Juventudes por la paz que se había celebrado en Nueva York entre el 16 y el 24 de agosto y había decidido quedarse en el país

60 González, 2012, pp. 329-330.

61 American Catholic University Archive (ACUA). Brookland, Washington DC, Estados Unidos. National Catholic Welfare Conference, International Affairs, Spain 1938-1964, Basques, Box 51, Folder 11. Carta sobre la delegación vasca de William Montavon a Michael J. Ready, 3-101938, Washington DC. Esta asociación formaba parte de la North American Committee to Aid Spanish Democracy. Durante el congreso de Juventudes por la Paz, Lombana se entrevistó con Eleanor Roosevelt a la que pudo explicar sucintamente la trágica situación que atravesaba el País Vasco, pidiéndole la ayuda y colaboración de Estados Unidos. También se puso en contacto con asociaciones de jóvenes cristianos. Anasagasti, 2013. 
para realizar una gira propagandística en colaboración con las Juventudes Libertarias de España y de Cataluña ${ }^{62}$. La delegación consideró esta actitud, por la imagen de desunión que ofrecía, como algo contraproducente para el Gobierno de Euzkadi y para el partido, y por eso Irala le pidió que evitara cualquier vinculación pública con ese grupo anarquista para impedir que esta perjudicara la labor vasca ante los medios católicos. No obstante, Lombana hizo caso omiso, respondiendo que contaba con las credenciales y el respaldo del PNV. Irala aclaró a Montavon que la única organización que representaba los intereses del Gobierno vasco era la delegación de Nueva York y que cualquier otra institución individual o colectiva no podía vincularse directa o indirectamente -aunque pudiera entenderse que actuara en nombre de un partido que formaba parte del Gobierno- a las actividades que la delegación vasca desempeñaba en Estados Unidos. De este modo, instaba al representante de los católicos estadounidenses a que les desligaran de los proyectos en los que pudiera participar Lombana a título individual o en representación del PNV ${ }^{63}$.

A pesar de estas apreciaciones de Irala, Montavon continuó sospechando de las actividades de la delegación. Desde su punto de vista -muy influido por las tesis franquistas procedentes del sacerdote y propagandista Constantino Bayle ${ }^{64}$ y del

62 Martí y Rey, 2003, p. 169.

${ }^{63}$ ACUA. Brookland, Washington DC, Estados Unidos. National Catholic Welfare Conference, International Affairs, Spain 1938-1964, Basques, Box 51, Folder 11. Carta sobre la delegación vasca de William Montavon a Michael J. Ready, 3-10-1938, Washington DC.

${ }^{64}$ Constantino Bayle, sacerdote jesuita de origen extremeño, publicaba asiduamente artículos a favor de los sublevados en el órgano de prensa del Centro de Información Católica Internacional -cuya sede se encontraba en Burgos-, De Rebus Hispaniae, que eran enviados periódicamente a la NCWC y en los que solía definir a los nacionalistas vascos como enemigos del catolicismo y aliados de los rojos. En una ocasión avisó a Montavon de dos hechos que debía tener en cuenta a la hora de relacionarse con los representantes vascos en Estados Unidos: 1. Que conociendo que el papa Pío XI había condenado, en el párrafo no 58 de su encíclica Divini Redemptoris del 19 de marzo de 1937, la cooperación con el comunismo en cualquier campo, los separatistas vascos colaboraron con los republicanos tanto en el gobierno como en la guerra. 2. Los obispos españoles, incluido al obispo de Vitoria - de ideología nacionalista vasca- estaban a favor del movimiento nacional y los separatistas vascos estaban contra este. ACUA. Brookland, Washington DC, Estados Unidos. National Catholic Welfare Conference, International Affairs, Spain, 1938-1964, Basques, Box 51, folder 11. Carta de C.J. Bayle a W. Montavon, 2-3-1939, Burgos, p. 6. A este respecto cabe señalar que tanto Mateo Múgica, Obispo de Vitoria, como Marcelino Olaechea, Obispo de Pamplona, indicaron en agosto de 1936 a través de una carta pastoral al PNV que no se opusiera a la sublevación. Aún y todo, Múgica fue acusado de ser simpatizante del PNV y los sublevados presionaron al Vaticano para que fuera trasladado de su diócesis, que abandonó en octubre de 1936. Ya en el exilio, Múgica siguió sin comprender la actitud del PNV, pero denunció el fusilamiento de sacerdotes por los franquistas y la persecución contra los católicos vascos y se negó a firmar la Carta Colectiva de los obispos españoles a favor de los alzados. Más tarde, la postura de Múgica evolucionó, hasta reconocer públicamente el acierto de la postura del PNV en 1936. Véase Botti, 2007, pp. 451-489; Pablo, 2003, pp. 115-141. 
cónsul Juan Francisco de Cárdenas ${ }^{65}$ - aunque los vascos hubieran dado muestras de su catolicismo y del apoyo que gozaban entre buena parte de los católicos europeos, formaban parte del gobierno republicano español-que conceptuaba de perseguidor, torturador y ejecutor de miles de personas religiosas-, y además lo representaban legalmente en Estados Unidos. En este sentido Montavon escribió a Ready:

Personally, I am not sure that Mr. Antonio de Irala has credentials which warrant him in requesting this formal cooperation between the Basque Delegation in the United States and the National Catholic Welfare Conference. From Mr. De Irala's conversation I get the impression that his Delegation and the Basque Government which he represents are not in good standing with the ecclesiastical authorities in that part of Spain which is administered by the Nationalists. There being no ecclesiastical authorities in the rest of Spain, it seems apparent that Mr. De Irala has no credentials that would justify any formal relationship between his Basque Delegation and the National Catholic Welfare Conference. However, I have no hesitancy in saying that Mr de Irala showed convincing evidences of his Catholicity ${ }^{66}$.

Distintas fueron las conclusiones extraídas por Irala de la conversación con Montavon. En una carta fechada en 11 de octubre de 1938, el delegado vasco indicó al lehendakari que la jerarquía católica estadounidense recibiría con entusiasmo la versión que los vascos pudieran ofrecerles como canal de información complementario. Irala creía que, por esta vía, podrían llegar a cambiar la postura de la NCWC respecto a la guerra de España, sobre la base de que ambos habían coincidido en aspectos relacionados con la precaria situación en la que se desenvolvía la sociedad civil y la difícil coyuntura que estaban atravesando las democracias europeas ante el auge de las ideologías totalitarias. Por ello, el delegado vasco solicitó la colaboración de Alberto Onaindía que, al ser sacerdote, tendría un más fácil acceso a la jerarquía católica estadounidense y podría agilizar las gestiones relativas a «conseguir que la disposición humanitaria incondicional de ciertos sectores católicos a favor de los vascos se extienda o por lo menos alcance

${ }^{65}$ En marzo de 1937, J. F. de Cárdenas se entrevistó con William Montavon en representación de los católicos españoles. El cónsul franquista le expresó que tenía la misión de coordinar las actividades católicas destinadas a la captación de simpatizantes por la causa de la España franquista. A raíz de ello, Cárdenas informó asiduamente y de manera epistolar de los eventos -a los que en más de una ocasión fue invitado por Miguel Echegaray-e informaciones relacionadas con, y a favor de, la España de Franco. Rey, 1996, p. 145.

${ }^{66}$ ACUA. Brookland, Washington DC, Estados Unidos. National Catholic Welfare Conference, International Affairs, Spain 1938-1964, Basques, Box 51, Folder 11. Memorándum de William Montavon a Michael J. Ready, 5-10-1938, Washington DC. 
eco general» ${ }^{67}$. Onaindía podría "trabajar para obtener una declaración, si no de la Jerarquía si de personalidades católicas, que muchas lo están deseando, por la paz en España, cese de odios y defensa de la convivencia ${ }^{68}$. Irala estimaba oportuno contar con su colaboración para desarrollar la estrategia de Aguirre de acercamiento tanto a los círculos católicos simpatizantes con los vascos como a los contrarios a estos $^{69}$.

Paralelamente a estos contactos, los delegados vascos prestaron atención preferente a buscar posibles contactos dentro de la Administración Roosevelt. Gracias a Michael Straight, amigo personal de Ramón de la Sota durante su etapa universitaria en Cambridge y agente de la Oficina de Gestión Económica del Departamento de Estado ${ }^{70}$, la delegación se puso en contacto con cuatro personalidades: Harry H. McBride, asistente del secretario de Estado Cecil Wayne Gray, antiguo oficial del consulado de Estados Unidos en Bilbao entre 1909-1910 y conocido de Ramón de la Sota y Llano; Thomas Corcoran, secretario general del Partido Demócrata; Eric C. Wendelein, agente de la Office of European Affairs; y su superior, el director adjunto Jay Pierrepont Moffat ${ }^{71}$. En varias de las reuniones que mantuvieron, los delegados ponderaron el destacado papel que habían tenido y tenían los vascos en las repúblicas sudamericanas, pues muchos exiliados que habían trabajado al servicio del Gobierno de Euskadi durante la Guerra Civil estaban ocupando importantes puestos gubernativos en ellas ${ }^{72}$. Los citados funcionarios estadounidenses se interesaron mucho por lo que Sota les transmitió sobre el papel que los exiliados vascos en Sudamérica podían desempeñar en beneficio del Gobierno de Estados Unidos, contribuyendo a la lucha contra la penetración político-cultural nazi y japonesa en las repúblicas

${ }^{67}$ Irargi. Bergara, España. GE-0041-05. Carta de Antón Irala a José Antonio Aguirre, 11-101938, Nueva York.

${ }^{68}$ Irargi. Bergara, España. GE-0041-05. Carta de Antón Irala a José Antonio Aguirre, 21-101938, Nueva York.

69 Irargi. Bergara, España. GE-0041-05. Carta de José Antonio Aguirre a Antón Irala, sin fecha, sin lugar. La delegación de Nueva York quiso que Montavon realizara alguna gestión ante la NCWC News Service (Oficina de Prensa). Virgil J. Vogel, fue uno de los periodistas que, trabajando para ambas publicaciones, denunció la grave injusticia que había cometido la prensa católica al etiquetar como "rojos» al presidente Aguirre y a los "faithful Church adherents as the liberty loving people of the Autonomous Basque Republic». Irargi. Bergara, España. GE-0041-05. Vogel, V. H. J. (1938). Editorial. The Catholic New World, 11-11-1938.

70 Jiménez de Aberasturi, 1999, p. 473; San Sebastián, 1991, pp. 37-38 y 61.

71 Irargi. Bergara, España. GE-0041-05. Informe sobre la organización del Departamento de Estado de Estados Unidos, sin fecha, sin lugar.

72 Irargi. Bergara, España. GE-0041-05. Informe no 132. 2a visita a Mr. Wendelein en el ministerio de Estado, 15-2-1939, sin lugar. 
latinoamericanas ${ }^{73}$. Durante la década de 1930, esta amenaza había comenzado a ser interpretada como un asedio de los totalitarismos europeos y asiáticos contra la democracia estadounidense, como Roosevelt había señalado en su discurso sobre el estado de la Unión del 4 de enero de 1939: "La defensa de la religión, la democracia y la buena fe entre las naciones es toda la misma lucha. Para salvar a una, debemos ahora armarnos mentalmente para salvar a todas ${ }^{74}$.

Para combatir este peligro, las agencias dependientes del US Foreign Service (Servicio de Asuntos Exteriores del Departamento de Estado) iniciaron un dispositivo de defensa contra un eventual ataque en suelo estadounidense y elaboraron un plan para instalar bases militares en los puntos estratégicos más vulnerables de las costas del Atlántico y el Pacífico ${ }^{75}$. En el desarrollo de esta estrategia defensiva, los exiliados vascos podían desempeñar un provechoso papel, porque, además de estar bien organizados, eran una comunidad cohesionada en torno a la autoridad del presidente Aguirre. Al realizar esta oferta de colaboración -que cobraría especial relevancia durante la II Guerra Mundial76-, la delegación vasca no solo buscaba que se levantara el embargo de armas sino también, como así solicitó, que el Departamento de Estado mediara ante el Gobierno de Franco -formado en enero de 1938- para que fueran conmutadas el máximo número posible de penas de muerte impuestas a ciudadanos vascos. La delegación repitió esta solicitud a distintas personalidades en múltiples ocasiones, como demuestra una carta fechada en septiembre de 1939 que Manuel Ynchausti envió a Mennen Williams -miembro del Partido Demócrata y ayudante del fiscal general-y en la que adjuntó un memorándum con el nombre de más de 160 ciudadanos vascos condenados a muerte que, en su mayoría, eran milicianos que habían depuesto las armas a cambio de salir de España ${ }^{77}$. Con intenciones similares se dirigieron cartas a Cordell Hull y al fiscal general Frank Murphy, vía George Messersmith -jefe de protocolo de la Casa Blanca- solicitando su intervención para la conmutación de estas penas; e incluso llevaron a cabo gestiones de igual significado a favor de Pedro María Irujo

73 Tim Weiner ha señalado que Roosevelt le entregó las primeras órdenes de batalla a Hoover el 8-5-1934 cuando le ordenó que investigara a los admiradores de Adolf Hitler en todos los frentes y las primeras pruebas apuntaron a que soviéticos, alemanes y japoneses habían estudiado concienzudamente los astilleros estadounidenses de ambos hemisferios. Weiner, 2012, pp. 107 y 112.

74 Peters, G. y Woolley, J. T., The American Presidency Project. Recurso electrónico disponible en: http://www.presidency.ucsb.edu/ws/?pid=1568 (consultado 15-1-2013)

75 Rockefeller Foundation Archive (RFA). Tarrytown, Nueva York, Estados Unidos. 4 NARA O-Washington DC Files, CIAA, Box 11, Folder 85. Informe sobre la fundación de una colaboración militar en Latinoamérica, sin fecha, Washington DC.

76 Esta cuestión ha sido abordada en Mota Zurdo, 2014, pp. 159-179.

77 NARA. College Park, Maryland, Estados Unidos. RG 59, State Department, box. 6415. Carta de Mennen Williams al Departamento de Estado, 7-9-1939, Washington DC. 
(ANV), hermano de Manuel Irujo, ministro en el Gobierno republicano por el PNV, ante el Departamento de Justicia y la fiscalía general. No obstante, la reiterada contestación fue la imposibilidad de intervenir en un asunto que no implicaba a ningún ciudadano estadounidense $y$, sobre todo, que comprometía la posición neutral de Estados Unidos ante el conflicto español ${ }^{78}$.

Pese a la tradicional política de aislamiento estadounidense respecto de los asuntos europeos, los artífices de la política exterior vasca sabían del importante papel que jugaba esta potencia en la esfera internacional. Así lo puso de manifiesto Manuel de la Sota: «a pesar del deseo de América de permanecer al margen de los incidentes políticos de Europa, los Estados Unidos son un factor en la balanza de poder en Europa y cualquier acción americana bien positiva o negativa, inevitablemente altera la balanza en Europa ${ }^{79}$. Por esta razón estimaron conveniente enviar información y mantener contacto con el Departamento de Estado, aunque no les prestara la atención que esperaban. Se trataba de poner en funcionamiento una política de la presencia que, al menos, preparara el terreno para estrechar las relaciones con Estados Unidos. Las expectativas eran buenas: así se lo hizo saber Sota al lehendakari cuando, solicitando instrucciones para una futura acción, le dijo que en el Departamento de Estado estaban bien afianzados, entablando nuevos contactos en cada reunión y creando lazos con los jefes de los principales departamentos relacionados con Europa (Office of European Affairs) y la Península Ibérica (Iberian Desk) ${ }^{80}$.

\section{FINANCIACIÓN PARA LOS REFUGIADOS, CONTRA-PROPAGANDA Y PROYECTOS DE ACTUACIÓN. LA NONATA SECCIÓN AMERICANA DE LA LIAB}

Teniendo en cuenta la importancia de las labores de lobbying sobre los grupos católicos estadounidenses, la delegación de Nueva York organizó un viaje a Idaho y Nevada con el fin de recabar apoyos a favor del Gobierno vasco, sondear la postura ante el conflicto español de los obispos de Boise y Reno -dos de los núcleos de población con más alto porcentaje devascosentodo Estados Unidos-ytratar de convencer a las colonias vascas de estos territorios, que eran mayoritariamente carlistas, de que la política del Gobierno de Euzkadi estaba del lado del catolicismo ${ }^{81}$. Antón Irala escribió a Montavon

78 NARA. College Park, Maryland, Estados Unidos. RG 59, State Department, Box. 6416, Leg. 852.00/9370. Carta de G.S. Messersmith a Frank Murphy, 4-11-1939, Washington DC.

79 Irargi. Bergara, España. GE-0041-05. Carta de Manuel de la Sota a José Antonio Aguirre, 16-2-1939, Nueva York.

80 lbíd.

81 ACUA. Brookland, Washington DC, Estados Unidos. National Catholic Welfare Conference, International Affairs, Spain 1938-1964, Basques, Box 51, Folder 11. Memorándum sobre la misión de Irala realizado por William Montavon para Michael Ready, 19-11-1938, Washington DC. 
para explicarle que una pequeña delegación realizaría ese viaje, presentándoselo, con el objetivo de recabar su apoyo, como un acto dirigido a neutralizar la posible influencia del comunismo entre la colectividad vasca en el oeste americano. Inmediatamente, el dirigente de la NCWC se dirigió a Ready insinuándole que, si esta organización católica apoyaba a la expedición vasca, obtendrían mayores beneficios para el catolicismo que mostrando indiferencia u hostilidad hacia la delegación de Gobierno vasco ${ }^{82}$. Aunque más de la mitad de los prelados de la NCWC defendiera la causa franquista-en contraste con sus bases sociales-, Ready se vio obligado a actuar pragmáticamente, respaldando la expedición vasca. Así, se dirigió a monseñor Thomas K. Gorman, obispo de Reno, para solicitarle que dispusiera la colaboración de las autoridades católicas de la zona en los eventos que organizara la delegación vasca en Reno ${ }^{83}$.

Las relaciones de la expedición vasca con el obispo de Reno fueron buenas, no así con el obispo de Boise, Edward J. Kelly. La delegación estaba informada de que, desde el inicio de la Guerra Civil, este prelado había emprendido una campaña de propaganda entre sus feligreses - principalmente vascos- en la que tergiversaba las informaciones procedentes de España y del Gobierno vasco en el exilio. En efecto, Kelly había lanzado desde el púlpito soflamas a favor de Franco, presentándolo como símbolo del respeto por la religión y la tradición ${ }^{84}$. Tras los primeros contactos, la delegación de Irala y Sota constató que no solo era un firme pro-franquista sino que además mantenía una difícil relación con la comunidad vasca de Idaho ${ }^{85}$. Esta situación provocó tensiones con Kelly, que vio en la delegación vasca la semilla de la discordia para su diócesis, sobre todo tras sugerirle que contara con la colaboración de sacerdotes vascos para oficiar misas en euskera y mantener viva la llama de la identidad nacional ${ }^{86}$. Esta es la importancia que daba Irala a esa sugerencia:

El vasco inmigrante siempre toma la emigración como cosa provisional pensando siempre en el momento de regresar a la Patria. Como consecuencia de esta provisionalidad y diferentes factores producto del ambiente, forma de trabajo, etc., el vasco por lo general sin perder la fe está ausente de toda práctica religiosa. A esto contribuye también en gran parte el problema del idioma. No hay entre ellos ningún sacerdote vasco, lo que hace que el problema espiritual de todas esas colonias vascas sea en realidad grave ${ }^{87}$.

82 Ibíd.

${ }^{83}$ ACUA. Brookland, Washington DC, Estados Unidos. National Catholic Welfare Conference, International Affairs, Spain 1938-1964, Basques, Box. 51, Folder 11Carta de Michael J. Ready al obispo Gorman, 29-11-1938, Washington DC.

${ }^{84}$ Ver Totoricagüena, 2002.

${ }^{85}$ Bieter y Bieter, 2005, p. 96.

${ }^{86}$ San Sebastián, 2010, p. 74.

87 Irala, 2003, p. 521. 
A pesar de las tensiones con las autoridades eclesiásticas de Boise y las más que mejorables relaciones con la NCWC, para Antón Irala, el momento que atravesaban las gestiones de la delegación a la altura de principios de 1939 no podía ser más esperanzador. Según sus impresiones, la sociedad estadounidense se mostraba unánimemente contraria a la España de Franco y opinaba -bastante ingenuamenteque esto solo era posible gracias a las simpatías conseguidas entre influyentes católicos estadounidenses afectos al bando franquista, como el cardenal de Nueva York Patrick Hayes, quien, a pesar de haber orado por la victoria de los sublevados e, inicialmente, haberse mostrado desabrido con el Gobierno de Euzkadi, ahora lo tenía en muy alta consideración ${ }^{88}$. Así se lo explicó al lehendakari: "os advierto que nuestro poder llega a mucho: en tono confidencial y muy reservado os puedo comunicar que para dentro de poco no nos podrá hacer la contra el Cardenal de Boston, que seguirá el mismo camino que el de Nueva York» ${ }^{89}$.

No solo se trabajó con esa parte de la Iglesia católica poco favorable a los propósitos del Gobierno vasco. El 25 de enero de 1939 Pedro Basaldúa -secretario de la Presidencia vasca- ordenó a Irala que se entrevistara con el cardenal George Mundelein, que representaba a ese otro sector que-desde la perspectiva de Aguirrepodría simpatizar con el Gobierno de Euzkadi. Irala debía explicarle la cuestión vasca desde una punto de vista que comparara la situación de los territorios vascos con el caso del reino de Yugoslavia, incidiendo en que este último Estado estaba compuesto por varias naciones o pueblos que habían aceptado formar parte de él bajo la fórmula de una federación y sin embargo habían sufrido el embate de un nacionalismo unitario que no reconocía diferencias nacionales. Debía igualmente despertar su interés por los niños vascos exiliados en Francia y cobijados en colonias católicas infantiles ideadas por el Ejecutivo vasco, e intentar lograr colaboración económica para su sostenimiento. También hacerle ver -en palabras de Aguirre«el peligro que para España, para la democracia y para el catolicismo ofrece la influencia que en los medios franquistas tiene ya en estos momentos la política alemana y de un modo concreto su paganismo ${ }^{90}$.

Siguiendo el plan establecido por Aguirre, en 1939 se aumentó el número de miembros de la delegación de Nueva York con la llegada de los periodistas Juan Aramburu y José Urresti, y el sacerdote Eustasio Arritola ${ }^{91}$. La delegación reforzó así su plantilla con la incorporación de delegados «de más edad y preparación», tal

${ }^{88}$ Irargi. Bergara, España. GE-0041-05. Fichero de propaganda realizado por los comisionados vascos Sota e Irala en Estados Unidos durante 1938, Nueva York.

89 Irargi. Bergara, España. GE-0041-05. Carta de Antón Irala a los honorables señores de la República de Bassano, 1939, París.

90 Irargi. Bergara, España. GE-0041-05. Carta de Pedro Basaldua a Antón Irala, 25-1-1939, París.

${ }^{91}$ Ordaz, 1995, pp. 179-198. 
como el lehendakari Aguirre había anunciado meses antes al embajador De los Ríos. Los nuevos miembros habían recibido órdenes muy concretas. La primera de ellas, realizar una campaña de propaganda dirigida a los vascos residentes en Nueva York y los Estados del oeste ${ }^{92}$. Con este fin, el lehendakari había solicitado previamente a Manuel de la Sota -encargado de la gestión y la dirección de espectáculos de arte y agrupaciones deportivas del Gobierno vasco- que estudiara la posibilidad de organizar, en colaboración con Valentín Aguirre y el Centro Vasco-Americano, un grupo de danza vasca, similar a Elai Alai ${ }^{93}$-que tanto éxito estaba obteniendo en Francia y Bélgica-, con fines propagandísticos y recaudatorios, además de servir para avivar el sentido de comunidad del exilio vasco y reclamar la atención de la opinión pública estadounidense. En consecuencia, se creó un Círculo de Estudios en torno al Centro Vasco-Americano de Nueva York para albergar las actuaciones del grupo Elai-Alai, se organizó un servicio de información permanente para el fomento del folklore y el deporte vascos, y se proyectó una gira del combinado de fútbol del equipo Euzkadi por Estados Unidos ${ }^{94}$.

El plan de propaganda sobre el oeste contemplaba otros aspectos. El lehendakari recomendó a Irala y Sota que dirigieran su atención sobre California, Idaho y Nevada con el fin de lograr un mayor número de suscripciones a Euzko Deya, y a tantear la posibilidad de nuevos asentamientos de vascos afines al nacionalismo -para reducir la influencia de los carlistas- y de colocación de mano de obra -relacionada con el pastoreo- de jóvenes vascos en la zona ${ }^{95}$. Incluso, como abordaremos más adelante, se proyectó la creación de una subdelegación en Boise, dependiente de la de Nueva York, desde la que realizar labores de propaganda, como la edición de una revista o la organización de actividades folklóricas de temática vasca, bajo la dirección de Jon Bilbao.

La segunda misión que Aguirre había encargado a los nuevos miembros de la delegación de Nueva York era servirse de los medios católicos como instrumento de presión e influencia sobre el presidente Roosevelt. José Urresti, cuñado de Manuel de la Sota, miembro de la comisión de propaganda del Gobierno vasco y encargado de las finanzas de la delegación, y Juan Aramburu, colaborador de la agencia de prensa francesa Havas, debían buscar simpatizantes, afines al catolicismo y a los nacionalistas vascos, entre periodistas de diarios de gran tirada, como The New York

92 Irargi. Bergara, España. GE-0041-05. Certificados de los comisionados vascos a Estados Unidos firmados por Pedro Basaldúa, secretario general del Gobierno vasco, 12-8-1938, sin lugar.

93 Organización de danza infantil vasca fundada por el guerniqués Segundo Olaeta. Granja y Echániz, 1998, p. 119 y ss.; Arana Martija,1977.

94 Irargi. Bergara, España. GE-0041-05. Carta de Pedro Basaldúa a Antón Irala, 12-9-1938, París. Véase Estomba, 2007, pp. 791-816.

95 Irargi. Bergara, España. GE-0041-05. Carta de José Antonio Aguirre a Manuel de la Sota, 1939, sin lugar. 
Post, The New York Herald Tribune, The Chicago Tribune, The Daily Worker y The New Masses $^{96}$. Asimismo, Eustasio Arritola tenía que reunirse con las principales instituciones católicas, con el fin de reorientar sus opiniones sobre los vascos. Irala hubiera preferido la presencia de Alberto Onaindía, quien tenía prestigio entre los católicos franceses y podía ganarlo también entre los estadounidenses, pero el canónigo vasco no podía abandonar su cargo de delegado del Gobierno vasco ante la Liga Internacional de Amigos de los Vasco (LIAB, en sus siglas en francés) en Francia ${ }^{97}$. En su lugar, fruto de una decisión tomada sin excesiva reflexión, Irala recibió la ayuda del mencionado sacerdote Arritola, antiguo capellán de Lequeitio (Vizcaya) y un desconocido fuera del País Vasco, cuya operatividad durante estos años fue nula por su escasa capacidad para las negociaciones (aparte de que hubiera preferido ser destinado a un país castellanoparlante $)^{98}$.

Durante los primeros meses de 1939 Antón Irala regresó a Francia a petición del lehendakari y Manuel y Ramón de la Sota se pusieron al frente de las actividades de la delegación de Nueva York, ocupando el primero de estos el cargo de delegado ${ }^{99}$. En esos momentos, la situación de la guerra en España era desesperanzadora, pues se estaba produciendo el colapso absoluto y la caída de Cataluña ante el avance de los sublevados. Desde la conferencia de Múnich de septiembre de 1938, Franco se sentía victorioso y respaldado por la comunidad democrática internacional para acabar rápidamente con el conflicto y así evitar una guerra a escala europea. La zona controlada por las autoridades republicanas parecía tener los días contados. El Gobierno de Euzkadi organizó un dispositivo para preparar la evacuación al sur de Francia de los refugiados vascos que se encontraban en Cataluña, porque, como había dicho el lehendakari Aguirre, «a todo trance deseamos evitar la emigración a América» ${ }^{100}$. Para él, la emigración transoceánica significaba alejarse demasiado del territorio vasco en caso de que el conflicto español provocara el estallido de una guerra a escala europea en la que, si los totalitarismos eran derrotados -incluida la España franquista aliada de Hitler y Mussolini-, los exiliados vascos podrían retornar a la Península. Entre 1938 y 1939, el Gobierno vasco se había visto superado por el significativo número de personas que se encontraban fuera del país y necesitaba

${ }_{96}$ Irargi. Bergara, España. GE-0041-05. Fichero de propaganda realizado por los comisionados vascos Sota e Irala en Estados Unidos durante 1938, Nueva York.

97 Cal, 2012, p. 204 y ss. La LIAB fue una institución político-benéfico-asistencial fundada oficialmente en París el 16 de diciembre de 1938 por personalidades vascas y francesas, a cuya cabeza se encontraba el cardenal Verdier, arzobispo de París. Su principal misión: dar cobertura legal y asistencial a los refugiados vascos. Jiménez de Aberásturi, 1999, p. 93.

98 Martínez, 2007, p. 59.

99 Angulo, Álvarez y Sanz, 2010, p. 176.

100 Irargi. Bergara, España. GE-0041-05. Carta de J.A. Aguirre a M. De la Sota, 1939 (sin fecha exacta), sin lugar. 
fondos para mantener la infraestructura desplegada en Francia ${ }^{101}$. De hecho, el Gobierno vasco invertía más del 34 por 100 de su presupuesto en el Departamento de Asistencia Social, que dirigía el socialista Juan Gracia, consejería que, entre otras cosas, se encargaba de la atención humanitaria. Por esta razón, el PNV y sus consejeros en el Gobierno optaron por una estrategia orientada hacia el control de ese Departamento, tratando de convencer a las autoridades francesas que el exilio vasco, aparte de ser menos problemático, era diferente del español, y tejiendo una propia red de apoyo a los refugiados. Sin embargo, a principios de 1939, la escasez de fondos obligó a la directiva del PNV y del Gobierno vasco a tomar la decisión de que todo aquel que, presumiblemente, no tuviera problemas con las autoridades franquistas regresara al País Vasco ${ }^{102}$.

Aun así, existían nutridos grupos de exiliados vascos en Francia que necesitaban atención, junto con otros que, aún en Cataluña, se encontraban a expensas de ser trasladados al otro lado de la frontera. En enero de 1939, Ramón de la Sota reinició los contactos con los representantes de la NCWC con el fin de solicitar su colaboración para favorecer económicamente el asentamiento de los evacuados. De hecho, según le indicó el delegado vasco a Michael J. Ready, José Urresti había llegado a Nueva York con el objetivo de pedir asesoramiento y financiación respecto a un plan del Comité National d'acqueil aux Basques para evacuar a 5.000 niños vascos desde Cataluña hasta Francia. Durante la reunión, Sota y Urresti señalaron que el Gobierno francés les había prometido su colaboración en el traslado de 22.400 niños que se encontraban en los alrededores de la frontera catalana (una cifra con seguridad exagerada, si tenemos en cuenta que bastantes niños fueron repatriados tras la caída de Bilbao en 1937) ${ }^{103}$. La mermada Hacienda vasca se estaba haciendo cargo de los gastos del alojamiento de las colonias infantiles creadas en el suroeste de Francia, del programa educativo católico impartido por sacerdotes, y de la manutención de los refugiados, que suponía un coste diario que oscilaba entre 6 y 7 francos. Así se lo expusieron al secretario general de la NCWC:

The Basque refugees wherever they are in-exile, are under the jurisdiction and assisted by the Basque Government, who follows a policy of educating them in accordance with the wishes and instructions of their parents. Owing to the Catholicism of the Basque people, the problem of the

101 Irargi. Bergara, España. GE-0041-05. Carta de José Urresti a José Antonio Aguirre, 15-21939, Nueva York.

102 Pablo, Mees y Rodríguez, 2001.

103 Irargi. Bergara, España. GE-0041-05. Carta de Pedro Basaldúa a Antón Irala, 27-1-1939, París. Los cálculos de Jesús Alonso sobre todos los refugiados vascos en Cataluña que cruzaron la frontera durante 1939 indican que no fueron más de 50.000, lo cual indica que una cifra como la de 22.400 niños para esta etapa es cuando menos bastante abultada. Alonso, 2007, pp. 706-707. 
Catholic education of the children has been solved by organizing colonies supervised by Basque priests and Basque Catholic teachers, and with the help and cooperation of Catholic societies formed for the purpose ${ }^{104}$.

Tras exponerle la situación, el secretario general de la NCWC sacó su cartera, cogió su talonario, les extendió un cheque al portador por valor de 10 dólares y les dijo que hicieran uso de él como creyeran conveniente ${ }^{105}$. Con este gesto, la NCWC decidió no comprometerse y esquivar la petición de la delegación, manteniendo invariada su postura de simpatía hacia el bando nacional.

Concluida oficialmente la Guerra Civil española el 1 de abril de 1939, la delegación vasca de Nueva York, a través de Manuel Ynchausti, se volvió a poner en contacto con la NCWC para crear una sección americana de la Liga Internacional de Amigos de los Vascos, una organización -como hemos señalado- humanitarioasistencial con atribuciones políticas que servía de cobertura legal para el Gobierno vasco en Francia. De este modo, ya el 20 de octubre de 1939, el diario Euzko-Deya de Buenos Aires publicó una circular de la secretaría de LIAB en la que se instaba a todos los vascos emigrados a América a fundar una sección de esta institución en América Latina, divulgando este propósito entre juntas y centros vascos. La publicación señalaba:

América no puede permanecer insensible ante este drama. Es posible que exista más sangre vasca en este continente que en el europeo. [...] ¡Hay que salvar al pueblo vasco! [...] Agrupar a los amigos de los vascos, hijos de nuestra raza o simpatizantes simplemente; acudir en ayuda de los vascos exiliados, facilitándoles especialmente traslado y colocación donde puedan vivir honradamente con su trabajo. [...] Velar por la suerte de los niños abandonados o huérfanos y gestionar la libertad de los vascos recluidos en las cárceles, en los campos de concentración o en las brigadas de trabajadores forzados. [...] Hacer conocer los problemas históricos y actuales de Euzkadi, propagar y defender el respeto a sus libertades y derechos de la tradición social, política y religiosa del pueblo vasco. [...] Editar publicaciones periódicas, libros, folletos, que propaguen todos los trabajos que se realizan, para lograr la unión de todos los vascos, su recíproca ayuda en los países donde convivan y su colaboración a los fines señalados en los apartados anteriores ${ }^{106}$.

${ }^{104}$ ACUA. Brookland, Washington DC, Estados Unidos. National Catholic Welfare Conference, International Affairs, Spain 1938-1964, Basques, Box 51, Folder 11. Memorándum de José Urresti para Michael J. Ready, 4 de febrero de 1939, Nueva York.

${ }^{105}$ Irargi. Bergara, España. GE-0041-05. Carta de Ramón de la Sota a Pedro Basaldúa, 6-11939, Nueva York.

106 "Llamamiento a los vascos y simpatizantes de los vascos», Euzko Deya Buenos Aires, no 17, año I, 20-10-1939. 
Siguiendo estas directrices, Ynchaustillevó a cabo gestiones personales en Estados Unidos para poner en marcha la LIAB en este país. El vasco-filipino había llegado a Nueva York en agosto de 1939, tras haber mantenido contactos con el Cardenal Villeneuve en Canadá para que este colaborara en la creación de un comité de socorro a los vascos que, formado en federación con otros comités nacionales, tendría por objetivo la realización de una colecta anual destinada a sustentar las organizaciones vascas de asistencia humanitaria ${ }^{107}$. Este proyecto no gozó de la aprobación del prelado canadiense y llevó a Ynchausti a examinar otras vías en Estados Unidos, en muchos casos retomando el acercamiento ya iniciado por la delegación vasca en Nueva York.

A principios de septiembre de 1939, inició una serie de gestiones en el medio católico con el objetivo de recabar apoyos para crear la sección americana de la LIAB. Se entrevistó primero con el padre jesuita y profesor de Georgetown University, Wilfrid Parsons, con John LaFarge (editor asociado de la revista America), con Eleanor Roosevelt (primera dama de Estados Unidos y activista política proderechos humanos) y con Henry Taft (hermano del expresidente de Estados Unidos, Howard Taft $)^{108}$. Las sensaciones fueron buenas, pero a la vez desesperantes por las reticencias que varios de ellos mostraron hacia la propuesta de Ynchausti. Sin embargo, esto no fue impedimento para que este se mantuviera en la brecha. EI 2 de noviembre de 1939, bajo recomendación del cardenal Francis Spellman de Nueva York, envió una carta al arzobispo de Detroit, Edward Mooney, en la que le expuso los objetivos de la LIAB de ofrecer una cobertura legal de apoyo a los exiliados (cuidando de los niños huérfanos, ayudando a encontrar trabajo a los refugiados, interviniendo a favor de la liberación de presos vascos, etc.); de difundir una imagen positiva sobre los vascos en el extranjero; y de utilizar esta plataforma en América como asociación que legalmente diera cobertura a la labor del Ejecutivo presidido por Aguirre, ante las complicaciones que pudieran presentarse tras el reconocimiento del gobierno de Franco por parte de Estados Unidos, dado que los delegados vascos estaban registrados en el Departamento de Estado como agentes del Gobierno de la República ${ }^{109}$. Ynchausti gozó de buena reputación entre el episcopado estadounidense, gracias a las cartas de recomendación realizadas por Maritain, el cardenal Verdier y el obispo de Vitoria, Mons. Mateo Múgica ${ }^{110}$,

107 Larronde, 1998, pp. 115 y ss.

108 Larronde, 1998, pp. 103-104.

109 La sección europea funcionaba en Francia gracias a la colaboración de Francisco Javier Landaburu, Ernst Pezet, el Cardenal Verdier, François Mauriac y el Arzobispo de Burdeos, Edouard Herriot. Véase Larronde, 1998.

${ }^{110}$ ACUA. Brookland, Washington DC, Estados Unidos. National Catholic Welfare Conference, International Affairs, Spain, 1938-1964, Basques, Box 51, folder 11. Letter of introduction from his excellency Msgr. Mateo Múgica Urrestarazu, former Bishop of Vitoria, Euzkadi para Edward Mooney, sin lugar, sin fecha. 
y a testimonios como el del jesuita pro-franquista J. LaFarge ${ }^{111}$, que a pesar de su idea general sobre la guerra en España garantizó la integridad y catolicidad del representante vasco, apoyando su proyecto:

My willingness to cooperate with him in this request is not that I necessarily accept his views, which I have not had sufficient occasion to examine, but is motivated by the desire which I think many of us who have been and still are entirely sympathetic to Nationalist Spain feel, that the time is ripe now for a more thorough examination of the Basque situation than was possible while the war was going on. Mr. Ynchausti has the well established reputation of being an excellent Catholic and entirely disassociated from any Left Wing movement ${ }^{112}$.

El propósito de Ynchausti era que el memorándum Proposed organization. American Section of the International League of the Friends of the Basques, en el que se exponían los fines descritos anteriormente, se incluyera entre los temas a tratar del congreso anual de la United States Conference of Catholic Bishops, que se iba a celebrar en Washington en noviembre de 1939, y de esta manera conseguir apoyo económico y social para desarrollar el proyecto ${ }^{113}$. Este informe comenzaba señalando que, con el inicio de una nueva guerra en Europa en septiembre de ese año, las democracias habían olvidado el «día del alzamiento» en España, creyéndose que con el régimen de Franco se hubieran restaurado y garantizado el orden, la paz, la justicia y la religión en España. Por ello, desmintiendo que esto fuera así, destacaba la existencia de más de 150.000 exiliados vascos en Gran Bretaña, Bélgica y Francia, cifra exagerada a tenor de las investigaciones más recientes, que han cifrado su

111 LaFarge tuvo poca estima, sin embargo, por los derechos de los comunistas nativos y sus seguidores. A medida que la Guerra Fría se desarrolló a finales de los años cuarenta, hizo uso del club anticomunista más que nunca. También continuó su beligerante defensa del régimen de Franco en España. Durante los primeros años de la Guerra Fría, los católicos americanos encontraron algunos obstáculos para su entrada dentro de la normalidad cultural. El evidente papel de los católicos en la cruzada anticomunista de posguerra facilitó ampliamente su completa aceptación dentro de la sociedad americana. Pero ahora, en una especie de nativismo invertido, los católicos fueron estigmatizados como los izquierdistas, como enemigos extranjeros y llamados antiamericanos. Southern, 1996, p. 276.

112 ACUA. Brookland, Washington DC, Estados Unidos. National Catholic Welfare Conference, International Affairs, Spain, 1938-1964, Basques, Box 51, folder 11Carta de John LaFarge a Michael J. Ready, 27-10-1939, Nueva York.

${ }^{113}$ ACUA. Brookland, Washington DC, Estados Unidos. National Catholic Welfare Conference, International Affairs, Spain, 1938-1964, Basques, Box 51, folder 11. Carta de Manuel Ynchausti a Edward Mooney, 2-11-1939, Nueva York. 
número en unos $79.500^{114}$. Todos ellos -se destacaba en el memorándum- eran hombres, mujeres y niños sin ningún tipo de posibilidad de volver de forma segura a su hogar, ni de subsistir económicamente en el extranjero.

Por esta razón, la creación de una sección americana de la Liga Internacional de Amigos de los Vascos podría ser una gran ayuda para la ya constituida y en funcionamiento sección francesa, a la que le resultaba imposible gestionar todo el trabajo humanitario necesario ante el estallido de la guerra en Europa. Para cumplir con esta misión, la sección americana de la LIAB se dividiría, como la francesa, en dos comités. Por un lado, un "Comité de Socorro» encargado de reunir a todos los vascos, ayudar al asentamiento de los exiliados, facilitar la unión de las familias dispersas, promover la liberación de vascos en prisión y cuidar del bienestar de los niños huérfanos. Una segunda comisión «de intereses generales» tendría el objetivo de organizar un centro de información que ofreciera documentación sobre los problemas actuales e históricos de las provincias vascas y sobre la defensa del respeto por los derechos y libertades de las tradiciones políticas, sociales y religiosas del pueblo vasco ${ }^{115}$. En respuesta a su petición, Mooney, sabedor que presidiría la conferencia anual de obispos, contestó que anotaba su petición y que sometería a consideración de los obispos este memorándum durante su reunión anual. No obstante, subrayaba que no podía asegurar que el tema se discutiera en la reunión, pues era bastante inusual que en este tipo de eventos se tomaran medidas conjuntas sobre estos asuntos y bastaba con la oposición de un solo obispo para hacerlo fracasar. Aun así, intentaría que el comité de obispos encargado de estas gestiones emitiera algún tipo de orden al respecto ${ }^{116}$.

\section{CONCLUSIONES}

A pesar de sus esfuerzos, el vasco-filipino no consiguió crear la sección americana de la $L I A B$, pues el asunto no se tomó en consideración en la reunión anual de obispos de Estados Unidos y tampoco contó con el apoyo de la NCWC, en parte, debido a la influencia de la propaganda franquista sobre esta última. Sin embargo, Ynchausti no cejó en su empeño en impulsar la creación de la Liga en Estados Unidos. De hecho, el 6 de diciembre de 1939 Ynchausti informó a Francisco

114 Alonso, 2007, pp. 693 y ss.

115 ACUA. Brookland, Washington DC, Estados Unidos. National Catholic Welfare Conference, International Affairs, Spain, 1938-1964, Basques, Box 51, folder 11. Proposed organization. American Section of the International League of the Friends of the Basques, 3-10-1939, Nueva York, p. 1-4.

${ }^{116}$ ACUA. Brookland, Washington DC, Estados Unidos. National Catholic Welfare Conference, International Affairs, Spain, 1938-1964, Basques, Box 51, folder 11. Carta de Edward Mooney a Ynchausti, 10-11-1939, Detroit (Ohio). 
J. Landaburu de que había logrado la colaboración de Carlton J.H. Hayes, prestigioso historiador católico de la Columbia University, aunque lamentaba que las gestiones en los medios católicos estadounidenses fueran tan desalentadoras ${ }^{117}$. De todos modos, en enero de 1940, con el fin de formar esta institución, se propuso alquilar una oficina en el Rockefeller Center, publicar un folleto sobre la vida de los refugiados vascos en Francia e incluso financiar un boletín que reprodujera noticias sobre este exilio, con el fin de establecer un centro de información al servicio de la inmigración vasca $^{118}$. Sin embargo, como se desprende de una carta enviada por Manuel Irujo a Ynchausti, a mediados de agosto de 1940, como preludio de un fracaso, la sección americana aún seguía sin constituirse.

La Liga Internacional de Amigos de los Vascos constituye un éxito, pese a la obligada catalepsia de la sección francesa, en la que se centraba su vida. Me parece excelente idea la de restaurarla ahí con la plenitud de vida que su generosidad permite y que nuestro ulterior concurso sabrá apoyar, hasta donde sea necesario. Agradeceré mucho a Ud. tenga la bondad de ponerme al corriente de cuanto a esta institución pueda convenir y de sus movimientos personales. Ud. sabe bien con cuánto interés recibí la sugestión [sic] y cómo me preocupa su desarrollo ${ }^{119}$.

A pesar de las esperanzas de Irujo y del apoyo recibido a esta iniciativa tanto por Hayes como por Frank Murphy, fiscal general de Estados Unidos que durante su estancia como gobernador de Filipinas estrechó amistad con Ynchausti, la LIAB nunca llegó a constituirse en Estados Unidos.

En conclusión, estos primeros acercamientos de la diplomacia vasca al medio estadounidense, que fueron el principio de un contacto continuo y con altibajos, extendido hasta la rehabilitación del Gobierno vasco en territorio peninsular en 1979, formaron parte de una potente estrategia liderada por José Antonio Aguirre. Una estrategia atlantista que consistió en atraerse el apoyo de las potencias democráticas y que, tras el inicio de la II Guerra Mundial, se centró en obtener el favor de Estados Unidos, al que ofrecieron la colaboración incondicional de los vascos en la lucha contra el Eje, con la esperanza de que el gigante norteamericano diera un impulso clave a las iniciativas antifranquistas si salían victoriosos del conflicto.

Como se ha visto, durante esta fase inicial, la estrategia de la dirección vasca fue interesante e ilusionante: crearon una delegación en Nueva York; llevaron a cabo iniciativas propagandísticas de naturaleza antifranquista; buscaron y obtuvieron

117 Jiménez de Aberásturi, 1999, p. 94, n. 133.

118 Larronde, 1998, p. 111.

119 Carta de Manuel Irujo a Ynchausti, 20-8-1940, Londres, Archivo personal de Manuel Ynchausti, en Larronde, 1998, p. 105. 
algunos canales de financiación -si bien, insuficientes-; y estuvieron al frente de las iniciativas para promover el levantamiento del embargo de armas impuesto por Estados Unidos a la España republicana. De hecho, como se ha podido comprobar, los delegados vascos buscaron -a través de diferentes medios- acercarse a la opinión pública católica estadounidense para ganarse su simpatía. Su objetivo: conseguir un canal de comunicación directo con la Casa Blanca, con la idea de que si contaban con su ayuda podrían presionar y convencer al Gobierno Roosevelt de que revocara su apoyo a la política de No Intervención. Pero, al mantenimiento de la política de No Intervención por parte del Gobierno de Estados Unidos - política que fue motivada por las presiones de influyentes funcionarios del Departamento de Estado- siguió el rápido reconocimiento del Gobierno franquista el 1 de abril de 1939.

Quizá este gesto de los norteamericanos tendría que haber obligado a los vascos a cambiar de estrategia, pero, la verdad, no fue así por la situación inicial en la que se encontraban sus contactos. Por tanto, el reconocimiento del Gobierno franquista no precisó que los dirigentes vascos modificaran drásticamente su estrategia, cosa que sólo hicieron durante la II Guerra Mundial. Lo que hizo la dirección política vasca en la coyuntura de la primavera-verano de 1939, fue, tan solo, dar un paso al frente y dotar de mayor vehemencia a los argumentos utilizados en su estrategia. Así pasó centrar su discurso en subrayar a sus interlocutores estadounidenses que la naturaleza del Gobierno de la España franquista era profundamente antidemocrática.

Comenzaron a ser escuchados. Por ello, a partir de ese momento, Estados Unidos ocupó la primera plana de la agenda política del Gobierno vasco en el exilio. Su insistencia acabó propiciando unas relaciones fluidas con Estados Unidos, hasta el punto de colaborar con ellos en materia de espionaje e información durante la II Guerra Mundial.

\section{BIBLIOGRAFÍA}

Alonso, J. (2007). El primer exilio de los vascos 1936-1939. Historia Contemporánea, 35, 683-708.

Alonso, T. (1990). La economía de entreguerras. La gran depresión. Madrid: Akal.

Alpert, M. (1996). Del embargo a la neutralidad: Estados Unidos y la guerra civil española. Historia 16, 248, 12-20.

Álvarez, O. y Sanz, E. (2011). El exilio institucional: el Gobierno autonómico vasco y sus delegaciones en el exterior. Eusko Ikaskuntza-EuskoNews, 564, 2-4, en http://www.euskonews.com/0564zbk/kosmo56401es.html 
Álvarez, O.; Sanz, E. y Angulo, A. (2010). Delegaciones de Euskadi, (1936-1975). Vitoria: Servicio Central de Publicaciones del Gobierno Vasco.

Ambrosius, LI. E. (2002). Wilsonianism: Woodrow Wilson and his Legacy in American Foreign Relations. New York: Palgrave MacMillan.

Anasagasti, I. (2013). Un jelkide en Nueva York. El blog de Iñaki Anasagasti, en http://ianasagasti.blogs.com/mi_blog/2013/03/un-jelkide-en-nueva-york. html (consultado el 5-5-2015).

Anasagasti, I. y Erkoreka, J. (2013). A Basque Patriot in New York: José Luis de la Lombana y Foncea and the Euskadi Delegation in the United States. Reno: Center for Basque Studies.

Anderson, J. M. (2003). The Spanish Civil War: A History and Reference Guide. Westport: Greenword Press.

Arana Martija, J. A. (1977). Elai Alai, primer grupo coreográfico del País Vasco. Gernika: Gernika Kultur Elkartea/Elexpuru.

Aron, R. (1973). La República Imperial. Madrid: Alianza.

Arrieta, L. (2007). Europa. La política europeísta del PNV en el exilio (1945-1977). Madrid: Tecnos.

Arrieta, L. (2009). Landaburu, el alavés europeísta. Sancho el Sabio, 31, 199-220.

Bieter, J. y Bieter, M. (2005). Un legado que perdura. La historia de los vascos en Idaho. Vitoria-Gasteiz: Gobierno Vasco.

Bosch, A. (2005). Convertirse en americanos. Las minorías étnicas y las dos guerras mundiales en Estados Unidos. Ayer, 58, 229-252.

Bosch, A. (2009). Historia de Estados Unidos (1776-1945). Barcelona: Crítica.

Bosch, A. (2012). Miedo a la democracia. Estados Unidos ante la Segunda República y la guerra civil española. Barcelona: Crítica.

Botti, A. (2007). La iglesia vasca dividida: cuestión religiosa y nacionalismo a la luz de la nueva documentación vaticana. Historia Contemporánea, 35, 451-489. 
Cal, R. (2012). Alberto Onaindia, propagandista contra el franquismo. Miguel Hernández Communication Journal, 3, 193-215.

Conde, A. de y Burns, R. D. (2001). Encyclopedia of American Foreign Policy. New York: Charles Scribner's Sons.

Conklin, G. (1936). The New Republic Anthology 1915-1935. New York: Dodge Publishing Company.

Estomba, F. (2007). El equipo Euzkadi: del mito político a la realidad histórica (19371939). Historia Contemporánea, 35, 791-816.

Fox, S. (2010). Misión imposible: la embajada en Washington de Fernando de los Ríos. En A. Viñas (ed.), Al servicio de la República. Diplomáticos y Guerra Civil (pp. 155-175). Madrid: Marcial Pons.

Fusi, J. P. (1979). El problema vasco en la II República. Madrid: Turner.

Fusi, J. P. (1984). El País Vasco: pluralismo y nacionalidad. Madrid: Alianza.

Fusi, J. P. (2002). El País Vasco 1931-1937: autonomía, revolución y guerra civil. Madrid: Biblioteca Nueva.

Garrido, I. y Lekuona A. (2006). Las raíces del árbol en el exilio. Las biografías de los consejeros del primer Gobierno de Euzkadi. Oñati: IVAP.

Goiogana, I. (2009). Antón Irala y la primera delegación del Gobierno Vasco en los EEUU. Hermes, 31, 84-90.

Goiogana, I. y Bernardo, I. (2006). Galíndez: la tumba abierta. Guerra, exilio y frustración. Bilbao: Fundación Sabino Arana.

González, J. L. (2010). Leocadio Lobo. Un sacerdote republicano (1887-1959). Hispania Sacra, 62(125), 267-309.

González, J. L. (2012). La guerra civil española y la conferencia de obispos norteamericana. Hispania Sacra, 64(Extra I), 315-341

Granja, J. L. (2003). El siglo de Euskadi. El Nacionalismo Vasco en la España del Siglo $X X$. Madrid: Tecnos. 
Granja, J. L. y Echániz, J. A. (1998). Gernika y la Guerra Civil. Symposium: 60 aniversario del bombardeo de Gernika (1997). Gernika-Lumo: Gernikazarra Historia Taldea.

Hills, G. (1984). Telegramas cruzados entre José Antonio Aguirre y Manuel Irujo entre junio y noviembre de 1938. Vasconia, 2, 275-299.

Jenkins, Ph. (2002). Breve historia de Estados Unidos. Madrid: Alianza.

Jiménez de Aberasturi, J. C. (1999). De la derrota a la esperanza: políticas vascas durante la Segunda Guerra Mundial (1937-1947). Oñati: IVAP.

Kennedy, D. M. (2005). Entre el miedo y la libertad Los EEUU: de la gran depresión al fin de la Segunda Guerra Mundial (1929-1945). Barcelona: Edhasa.

Larronde, J. C. (1998). Exilio y Solidaridad. La Liga Internacional de Amigos de los Vascos. Bidasoa: Bilbao.

Larronde, J. C. (1998). Manuel de Ynchausti, un mecenas inspirado (1900-1961), Bidasoa: Villefranque.

López Zapico, M. A. (2008). Las relaciones entre Estados Unidos y España durante la Guerra Civil y el primer franquismo (1930-1945). Gijón: Trea.

Martí, J. V. y Rey, A. (2003). El viaje de Félix Martí Ibañez a Norteamérica en busca de apoyos internacionales (agosto-diciembre, 1938). En J. LI. Barona (comp.), Ciencia, salud pública y exilio. España (1875-1939) (pp. 169-222). Valencia: Seminari d'estudis sobre la ciencia.

Martínez, S. (2007). Monseñor Antoniutti y el clero nacionalista vasco (julio-octubre de 1937). Sancho el Sabio, 27, 39-80.

Miralles, R. (1994). George Bonnet y la política española del Quai D’Orsay (19381939). Melanges de la Casa de Velázquez, 30(3), 113-141.

Montero, J. A. (2009). Diplomacia pública, debate político e historiografía en la política exterior de los Estados Unidos (1938-2008). Ayer, 75, 63-95.

Moradiellos, E. (2001). El reñidero de Europa. Las dimensiones internacionales de la guerra civil española. Barcelona: Península. 
Moreno, A. C. (2008). Los Servicios de Prensa extranjera durante el primer franquismo (1936-1945) (Tesis doctoral inédita). Alcalá de Henares: Universidad de Alcalá de Henares.

Mota Zurdo, D. (2014). José Laredogoitia Menchaca, el agente Gernika. Sancho el sabio: revista de cultura e investigación vasca, 37, 159-179.

Núñez X. M. (1995a). ¿Protodiplomacia exterior o ilusiones ópticas? El nacionalismo vasco, el contexto internacional y el Congreso de Nacionalidades Europeas. Cuadernos de sección Historia y Geografía, 23, 243-275.

Núñez X. M. (1995b). Relaciones exteriores del nacionalismo vasco. En S. de Pablo (ed.), Los nacionalistas. Historia del nacionalismo vasco, 1876-1969 (pp. 381417). Vitoria-Gasteiz: Fundación Sancho el Sabio.

Núñez X. M. (2006). ¡Fuera el invasor! Nacionalismos y movilización bélica durante la guerra civil española (1936-1939). Madrid: Marcial Pons.

Onaindia, A. (1974). Experiencias del exilio. Capítulos de mi vida, vol. II. Buenos Aires: Ekin.

Ordaz, M. A. (1995). La delegación vasca en Nueva York: una década bajo el punto de mira del FBI (1938-1947). Estudios de historia social y económica de América, 12, 179-198.

Ordaz, M. A. (1998). Características del exilio español en Estados Unidos (1936-1975) y Eugenio Fernández Granell como experiencia significativa, (Tesis Doctoral inédita). Madrid: Universidad de Alcalá de Henares.

Pablo, S. de (2006). Tierra sin paz Guerra civil, cine y propaganda en el País Vasco. Madrid: Biblioteca Nueva.

Pablo, S. de (2003). "La Guerra Civil en el País Vasco: ¿un conflicto diferente?», Ayer (50), pp. 115-141.

Pablo, S. de y Mees, L.; Rodríguez, J. A. (2001). El péndulo patriótico. Historia del Partido Nacionalista Vasco (1936-1979), Tomo II. Barcelona: Crítica.

Redondo, G. (1993). Historia de Ia Iglesia en España 1931-1939, Tomo II La Guerra Civil (1936-1939). Madrid: Rialp. 
Rey, M. (1996). Fernando de los Ríos y Juan F. Cárdenas: dos embajadores para la guerra de España (1936-1939). REDEN, 7(11), 129-150.

Rey, M. (1997), Stars for Spain: la guerra civil española en los Estados Unidos. A Coruña: Ediciones Do Castro

Roosevelt, F. D. (1937). Quarantine Speech. En http://millercenter.org/president/ speeches/detail/3310 (consultada el 5-3-2016).

Ruíz Manjón, O. (2007). Fernando de los Ríos. Un intelectual en el PSOE. Madrid: Síntesis.

San Sebastián, K. (1991). The Basque Archives. Vascos en los Estados Unidos (19381943). San Sebastián: Txertoa.

San Sebastián, K. (2010). J. A. Aguirre: Democracia cristiana y europeísmo en EE. UU. Hermes, 34, 72-81.

San Sebastián, K. (2014). El exilio vasco en América. Vitoria-Gasteiz: Gobierno Vasco.

Sánchez, J. M. (1992). Priest and Susepct Catholics: Visitors from Loyalist Spain to America. The Catholic Historical Review, 78(2), 207-216.

Sealander, J. (2003). The Failed Century of the Child. Governing America's Young in the Twentieth Century. New York: Cambridge University Press.

Southern, D. W. (1996). John LaFarge and the Limits of Catholic Interracialism 19111963. Baton Rouge: Lousiana State University Press.

Stiglitz, J. E. (2004). Macroeconomía. Barcelona: Ariel.

Thòmas, J. M. (2007). Roosevelt y Franco. De la guerra civil española a Pearl Harbor. Barcelona: Edhasa.

Totoricagüena, G. (2002). Boise Basques: Dreamers and Doers. Vitoria-Gasteiz: Gobierno vasco.

Ugalde, A. (1996). La actuación internacional del primer Gobierno vasco durante la Guerra Civil (1936-39). Sancho el Sabio, 6, 187-210. 
Ugalde, A. (1996). La Acción Exterior del Nacionalismo Vasco (1890-1939): Historia, pensamiento y Relaciones Internacionales. Oñati: IVAP.

Ugalde, A. (2000). Las relaciones internacionales del nacionalismo vasco (18901936) y del primer Gobierno Vasco (1936-1939). En F. Aldecoa y M. Keating (ed.), Paradiplomacia: las relaciones internacionales de las regiones (pp. 183201). Madrid: Marcial Pons.

Vogel, V. H. J. (1938). Editorial. The Catholic New World, 11-11-1938.

Weiner, T. (2012). Enemigos. Una Historia del FBI. Barcelona: Debate, Barcelona.

Wickenden, D. (1994). The New Republic Reader. Eighty Years of Opinion \& Debate. New York: Basic Books.

Zanca, J. A. (2009). El humanismo cristiano y la cultura católica argentina (19361959), (Tesis doctoral). Buenos Aires: Universidad de San Andrés. 